\title{
The Shared Pathoetiological Effects of Particulate Air Pollution and the Social Environment on Fetal-Placental Development
}

\author{
Anders C. Erickson ${ }^{1}$ and Laura Arbour ${ }^{1,2}$ \\ ${ }^{1}$ Division of Medical Sciences, University of Victoria, Medical Science Building, Room 104, P.O. Box 1700 STN CSC, \\ Victoria, BC, Canada V8W 2 Y2 \\ ${ }^{2}$ Department of Medical Genetics, University of British Columbia, C201, 4500 Oak Street Vancouver, BC, Canada V6H 3N1 \\ Correspondence should be addressed to Laura Arbour; larbour@uvic.ca
}

Received 12 July 2014; Accepted 21 October 2014; Published 26 November 2014

Academic Editor: Pam R. Factor-Litvak

Copyright (c) 2014 A. C. Erickson and L. Arbour. This is an open access article distributed under the Creative Commons Attribution License, which permits unrestricted use, distribution, and reproduction in any medium, provided the original work is properly cited.

Exposure to particulate air pollution and socioeconomic risk factors are shown to be independently associated with adverse pregnancy outcomes; however, their confounding relationship is an epidemiological challenge that requires understanding of their shared etiologic pathways affecting fetal-placental development. The purpose of this paper is to explore the etiological mechanisms associated with exposure to particulate air pollution in contributing to adverse pregnancy outcomes and how these mechanisms intersect with those related to socioeconomic status. Here we review the role of oxidative stress, inflammation and endocrine modification in the pathoetiology of deficient deep placentation and detail how the physical and social environments can act alone and collectively to mediate the established pathology linked to a spectrum of adverse pregnancy outcomes. We review the experimental and epidemiological literature showing that diet/nutrition, smoking, and psychosocial stress share similar pathways with that of particulate air pollution exposure to potentially exasperate the negative effects of either insult alone. Therefore, socially patterned risk factors often treated as nuisance parameters should be explored as potential effect modifiers that may operate at multiple levels of social geography. The degree to which deleterious exposures can be ameliorated or exacerbated via communitylevel social and environmental characteristics needs further exploration.

\section{Introduction}

Over the last decade, chronic exposure to ambient air pollution has become increasingly recognized as an important risk factor underlying adverse pregnancy outcomes (APOs) [1-9]. In parallel, the associations between socioeconomic status (SES) and APOs are among the most robust findings in perinatal research [10-12], which persist even in settings with universal access to health care [13-16]. While interest in the intersection between health and the social environment is long standing [17-19], renewed attention has been propelled by two independent progressions in quantitative research. The first is the popularization of multilevel statistical models and the ability to separate the individual-level effects from those of their encompassing social and physical environments [20-26]. The second is the emerging research on the biological effects of psychosocial stress on health and its modification by environmental factors. There is now mounting evidence that stress can interact with chemical exposures to exacerbate the toxic effect and the physiological response to a greater extent than either insult (stress or chemical) acting alone [27-31]. Furthermore, the accumulation of low-level exposures to multiple chemicals via multiple sources and pathways shows evidence of dose addition and synergism [32-34]. For example, synergism was observed between aqueous cigarette tar and other respirable particles (e.g., asbestos fibers, particulate matter, and diesel exhaust) [35]. Recognition of these interactions has been incorporated into several conceptual models and study designs of cumulative risk of chemical and nonchemical exposures [36-39] with models recently developed to identify these potentially double-exposed populations [40, 41]. Two complimentary reviews of these models have been recently published $[42,43]$.

Although the causes of APOs are multifactorial, the placenta plays the main intermediary role between the mother's physical and social environment and the fetus [44-50]. 
Importantly, a perturbed intrauterine environment inhibiting the fetal growth trajectory may also have long-term adult health implications as suggested by the developmental origins of disease hypothesis [51-53]. Therefore efforts to understand the underlying mechanisms of the physical and social environment that contribute to the disproportionate risk of APOs across the socioeconomic spectrum are required in order to target preventative and restorative interventions. This review will examine how the shared pathoetiological effects of exposure to particulate air pollution and SES act on the fetal-placental unit leading to adverse pregnancy outcomes. This will be accomplished by building on conceptual pathway models of air pollution and SES etiologic mechanisms on APOs [54, 55]. We review the role of the placenta in this context, describing its physiology and obstetrical pathologies followed by a description of particulate air pollution and its toxicokinetics in relation to placentation and how it can lead to APOs. We highlight specific indicators of SES and their biological pathways that intersect with air pollution exposure and how this may contribute to increased susceptibility for APOs. Potential implications and interventions are summarized in the conclusion. Our aim is for this review to be a resource for researchers interested in environmentalperinatal epidemiology. Understanding how correlated social and environmental exposures at times overlap to produce potentially synergistic and modifiable effects will help guide future research and intervention strategies with the aim to improve the overall health of the population [36-40].

\section{Person, Place, and Context: The Placental, Physical, and Social Environments}

2.1. The Placenta. The mammalian placenta is an intriguing and remarkable organ. Formed from two genetically distinct organisms, it is multifunctional and vital to fetal development yet situated outside the fetal body with a limited life span. Notable characteristics unique to humans and the Great Apes include deep interstitial implantation and a highly invasive hemochorial phenotype thus allowing the direct interaction of maternal blood and fetal chorionic tissues [56]. Interestingly, this particular aspect of placental evolution has less to do with nutrient transfer efficiency than previously thought and more likely implicates the highly regulated maternal-fetal immunological relationship [57-59].

The first trimester is a critical period in pregnancy involving implantation and initial placentation, two events highly susceptible to disturbance. The "Great Obstetrical Syndromes" [60] such as early/recurrent miscarriage, pregnancy induced hypertension and preeclampsia (PIH/PE), fetal growth restriction (FGR), placental abruption, prelabour rupture of the fetal membranes (PROM), and spontaneous preterm labour may share common etiological mechanisms arising from defective deep placentation (DDP) [61, 62]. Together, these conditions may complicate between 17 and $29 \%$ of all pregnancies [63] and are for the purpose of this review referred to collectively as APOs. Furthermore, these conditions may lead to epigenetic programming of adult disease susceptibility including obesity, diabetes, cardiovascular and reproductive diseases, all with their own substantial societal costs $[52,64-66]$. DDP refers to the shallow invasion of the placental bed into the maternal decidua and myometrium including incomplete remodeling of the uterine spiral arteries $[62,67]$. The latter is a vital event during which under normal conditions the endothelial lining of the spiral artery walls is remodeled to accommodate the inundation of maternal blood flow starting in the second trimester [68]. Spiral arteries that fail to undergo this vascular remodeling are not only narrower in diameter but also remain responsive to vasoconstrictive compounds such as stress hormones. The etiological trigger(s) leading to DDP are thought to involve either early placental oxidative stress which triggers an inflammatory response or, vice versa, an atypical inflammatory maternal immune response to the semi-allogenic fetal-placental unit leading to placental oxidative stress and further inflammation $[69,70]$. The difference between a normal and an affected pregnancy is a matter of degrees on a continuum with individual biological and behavioural variability nested within the social and physical environment [12, 24-26, 68, 69, 71-73].

2.2. The Physical Environment: Particulate Air Pollution. Air pollution is a general term used to describe the presence of agents (particulates, biologicals, and chemicals) in outdoor or indoor air that negatively impact human health. Several common air pollutants have been associated with APOs, including carbon monoxide (CO), nitrogen dioxide $\left(\mathrm{NO}_{2}\right)$, sulfur dioxide $\left(\mathrm{SO}_{2}\right)$, ozone, particulate matter $(\mathrm{PM})$, and polycyclic aromatic hydrocarbons (PAHs) [1]; however, attention has focused on the latter two compounds showing strong molecular evidence of cytotoxicity, mutagenicity, DNA damage, oxidative stress, and inflammation [55, 74-79]. While the observed risks of APOs in relation to air pollution tend to be modest, the population attributable risk can be quite large due to the pervasiveness of exposure to the general population [9]. Significant risks have been observed even in settings with relatively low ambient air pollution exposure $[80,81]$. Therefore, a small increase in risk can have a large public health impact. Preterm birth (PTB) and FGR are major risk factors of perinatal mortality and serious infant morbidities contributing to increased health care and societal costs [82-87].

Particulate matter $(\mathrm{PM})$ is a complex mixture of varying chemical and physical properties. It is defined according to particle size into the inhalable coarse fraction $\left(\mathrm{PM}_{10}, 2.5-\right.$ $10 \mu \mathrm{m})$, the fine respirable fraction $\left(\mathrm{PM}_{2.5}, \leq 2.5 \mu \mathrm{m}\right)$, and the ultrafine fraction (UFP, $\leq 0.1 \mu \mathrm{m}$ ). Their ubiquity and recognized human health risks have deemed them as toxic $[88,89]$. Characterizing PM by particle size is important for several reasons. First, particle size dictates the location of deposition in the respiratory system $[88,90]$. Second, particle size can give some indication of its general source and behaviour. For example, $\mathrm{PM}_{10}$ is mainly derived from mechanical processes such as windblown soil, pollen, minerals and dust from roads, farms, and industrial operations. $\mathrm{PM}_{10}$ tends to gravitationally settle in a matter of hours to days. Conversely, $\mathrm{PM}_{2.5}$ is a primary by-product of combustion and atmospheric reactions with precursor gases such as $\mathrm{SO}_{2}$, nitrogen oxides, ammonia, and volatile organic compounds (VOCs). $\mathrm{PM}_{2.5}$ 
can remain suspended in air for days to weeks and are consequently more prone to long-range transport. Precipitation accounts for $80-90 \%$ of $\mathrm{PM}_{2.5}$ removal from the atmosphere [88]. Third, the chemical composition is markedly different between $\mathrm{PM}_{10}$ and $\mathrm{PM}_{2.5}$ mixtures. Derived mainly from the Earth's crust, $\mathrm{PM}_{10}$ typically contains oxides of iron, calcium, silicon, and aluminum, whereas $\mathrm{PM}_{2.5}$ mixtures derived from anthropogenic combustion sources are mainly composed of sulphates, nitrates, ammonium, trace metals, elemental carbon, and organic hydrocarbons (e.g., PAHs) [88]. Chemical differences and relative proportions also differ within the $\mathrm{PM}_{10}$ and $\mathrm{PM}_{2.5}$ mixtures with regional (urbanto-rural) and interurban (urban-to-urban) differences as well as intraurban spatial variation [88, 91-93]. Therefore trimester and demographic differences in residential mobility and intraurban population differences are important study design issues to consider $[94,95]$. Finally, $\mathrm{PM}_{10}, \mathrm{PM}_{2.5}$, and UFPs differ by their toxicological mechanisms such as their oxidative potential, which may reflect their differences in size, surface area, and/or their chemical constituent compositions, although they tend to be correlated $[76,92,96,97]$. Transition metals such as copper, nickel, lead, chromium, iron, vanadium, and cobalt among other metals are variably present in ambient air absorbed to $\mathrm{PM}_{2.5}[92,93]$. Their direct oxidative action or redox potential to create reactive oxidative species (ROS) is one possible mechanism as to how $\mathrm{PM}_{2.5}$ induces oxidative DNA and protein damage $[78,97]$.

There is accumulating evidence that suggests UFPs may be the fraction of PM responsible for many of the adverse health effects reported in air pollution studies [78, 79, 97, 98]. UFPs are a small proportion by mass but make up a large proportion in particle number and have gone either unmeasured or misclassified as $\mathrm{PM}_{2.5}[88,98]$. Their small size facilitates better tissue penetration deep into lung alveoli and into epithelial cells restricting their clearance via macrophage phagocytosis [98]. Animal studies have shown that UFPs can translocate across the lung epithelium into blood circulation and accumulate in other organs, including the liver, spleen, kidneys, heart, brain, and reproductive organs [98]. The high surface area of UFPs favours the absorption of PAHs and possibly transition metals which has shown to localize in the mitochondria inducing major structural damage. This could be a possible explanation to UFP's exhibited higher oxidative potential compared to larger PM fractions of the same material [79]. Recent attention has been given to proinflammatory and endocrine-disrupting properties of diesel emissions, a major source of UFPs in ambient air [31, 99-101].

Polycyclic aromatic hydrocarbons (PAHs) are organic substances that constitute a class of over 100 individual chemical compounds made up of carbon and hydrogen atoms formed into rings [102]. While toxicological data exist for individual PAHs (benzo[a]pyrene being the most commonly used PAH indicator), they almost always occur as complex mixtures (e.g., soot, tobacco smoke, creosote, and diesel exhaust) [103]. Thus it is difficult and arguably futile to assess the toxicity of individual PAH components only to be compounded by the likelihood of interactions [75, 104, 105]. Combustion of organic matter and fossil fuels is the main source of atmospheric PAHs with their distribution and magnitude concentrated along transportation corridors (road and rail) and land-use areas with heavy industrial activities. However, main stream and environmental tobacco smoke (ETS) remain a leading source of PAH exposure [106]. PAHs are generally nonvolatile (i.e., stable) and have low water solubility. As a consequence, PAHs often bind to $\mathrm{PM}_{2.5}$ and UFP in the atmosphere. Residency times in the atmosphere depend on weather conditions, PAH molecular weight, and the emission source (e.g., stack versus tailpipe) with atmospheric deposition as the main source of PAHs to soil, vegetation, and surface water. Once in aquatic systems, PAHs are often found absorbed to suspended particles or bound to sediments settled on the bottom where they persist or are slowly biodegraded by microorganisms. While PAHs can bioaccumulate in some aquatic and terrestrial organisms, they tend to not biomagnify in food systems due to their metabolism in higher order species $[102,106]$. However, it is the inefficient clearance and action of the highly reactive $\mathrm{PAH}$ metabolites that are suspected to cause cytotoxicity, mutagenicity, DNA damage, oxidative stress, and tumorgenesis $[75,106]$.

Much of the work elucidating the mechanisms in which PM and PAHs elicit adverse cellular effects have been conducted using cardiovascular disease (CVD) and lung cancer as models [76-78, 97, 107-109]. Although seemingly different diseases, they share several similarities with DDP and APOs with respect to associated risk factors. First, both APOs and CVD related outcomes are associated with PM exposure levels which vary by SES $[40,110,111]$ but are also associated with other socially patterned risk factors such as smoking, poor or inadequate diet, psychosocial stress, obesity, and diabetes [12, 112-114]. CVD and APOs also share many other risk factors such as the presence of systemic inflammation and preexisting hypertension. Interestingly, $\mathrm{PIH} / \mathrm{PE}$ is a risk factor for maternal CVD later in life and also in the offspring if affected by IUGR [115-117]. CVD and disorders of DDP have similarly affected cellular tissues in their respective target systems (i.e., endothelial cells of the cardiovascular system and in the highly vascularised placenta) which are particularly susceptible to oxidative and inflammatory injury $[97,118]$. High plasma homocysteine concentrations are positively associated with vasculopathy and infarction in the placental-uterine and coronary systems increasing the risk of spontaneous PTB and CVD events, respectively $[119,120]$. Fittingly, high density lipoprotein cholesterol may be protective against spontaneous PTB and CVD events [120, 121]. Finally, PM and PAH-induced mutagenicity, cytotoxicity, DNA damage, and oxidative stress linked to lung cancer have also been observed in the fetal-placental unit $[122,123]$, and exposure early in pregnancy may contribute to the risk of congenital anomalies and early (subclinical) pregnancy loss [124-127].

2.3. The Social Environment: Socioeconomic Status, Diet, Smoking, and Allostatic Load. The social environment plays a significant role in maternal and perinatal health with indicators of low socioeconomic status (SES) consistently among the strongest predictors of adverse pregnancy outcomes [10-12]. The causal pathways in which SES contribute 
to APOs and ill health in general can be conceptualized in terms of "downstream" or mediating exposures, stresses, and behaviours acting on the individual through "upstream" society-level determinants such as poverty, poor education, income inequality, and social discrimination/marginalization over the lifespan [12]. Indicators of low SES associated with PTB and FGR include maternal anthropometry (prepregnancy BMI, height, and gestational weight gain), nutrition and micronutrient status, cigarette use, genital tract infections and inflammation, cocaine and other drug use, physically demanding work, quantity and quality of prenatal care, and psychosocial factors including anxiety, depression, and stress (e.g., lack of social, familial, and marital support, poverty or financial hardship, physical/verbal abuse, and neighbourhood crime) $[12,24,26,54]$. For the purpose of this review, the focus here will be on three that engage with the oxidative stress and inflammation pathways to potentially interact with exposure to particulate air pollution. They include (1) a diet-micronutrient pathway [55, 128131], (2) cigarette smoke exposure [35, 132-135], and (3) stress-mediated (allostatic) activation of the HPA-axis and corresponding glucocorticoid production [47, 72, 136-138].

Nutrition and diet can influence perinatal health in opposing directions. Poor/under-nutrition such as high fat/calorie dense food and low micronutrient intake is more prevalent among women from low SES backgrounds which may partly explain higher rates of some APOs [12, 139-142]. Conversely, adequate diet and micronutrient status provides resilience against oxidative stress and inflammation caused by various exposures including air pollution, allostatic stress, infection, or smoking $[55,118,128,129,131,143]$. Maternal exposure to mainstream or environmental cigarette smoke during pregnancy is associated with numerous APOs including congenital anomalies [127, 144-146]. Their exposure prevalence is associated with indicators of low SES as well as other socially patterned risk factors [147-149] and remains one of the most modifiable risk factors with potential for beneficial intervention. Other risk factors associated with low SES such as obesity, pre-existing and gestational diabetes, and hypertension $[13,113,150]$ also engage the oxidative stress and inflammatory pathways and could therefore also potentially interact with PM exposure to increase susceptibility to adverse effects as evidenced in studies of cardiovascular health $[114,151,152]$. Recent studies have observed increased risks of preeclampsia and gestational diabetes associated with measures of air pollution [153-156] with one study showing positive effect modification by preexisting and gestational diabetes [154]. Evidence shows that chronic life stressors associated with low SES at multiple levels of organization (individual, household, and community) result in a cumulative biological toll on the body affecting multiple systems and increasing susceptibility to numerous ailments [21, 157-160] including APOs $[15,26,161,162]$.

The concept of allostasis and allostatic load/overload has been proposed to describe the individual stress response to an event as a necessary and adaptive process thereby removing the implicit negative connotation attached to the term "stress" [163]. Stress can be positive or tolerable when it improves function and performance and may have long-term adaptive benefits. However, this may depend on available coping resources such as one's psychological resistance, resilience, and ability to recover. Negative or toxic stress occurs when real or perceived environmental/social demands, or the anticipation of such, become too extreme or unpredictable thereby exceeding one's (perceived) ability to cope (e.g., no sense of control, adverse childhood experiences, and other forms of trauma) $[164,165]$. Therefore, allostasis is the multisystem biological response that promotes adaptation using system mediators such as cortisol, (nor)epinephrine, vasopressin, renin, and glucagon, whereas allostatic load and overload is the cumulative toll (wear and tear) on biological systems after prolonged or poorly regulated (hyper/hypoactivated) allostatic responses $[165,166]$. For example, the cardiovascular system is extremely sensitive to stress in terms of increased blood pressure; however, metabolic disorders such as diabetes and obesity as well as immune function impairment are also linked to chronic stress. Furthermore, lifestyle coping mechanisms as a response to chronic stress have the ability to either buffer or exasperate the effect (e.g., exercise, diet, sleep, and social interactions or lack thereof) [163]. Therefore in light of the above, it is our belief that the fetal-placental unit is the site where the physical and social environments converge and interact to influence reproductive health which we describe further below.

Figure 1 illustrates the interconnectedness between particulate air pollution (PM/PAH) and SES on how they may act discretely or in a combined manner to yield APOs. Using Figure 1 as a guide, the following text will review the two major mechanisms (oxidative stress and inflammation) through which the physical and social environments are believed to negatively affect the fetal-placental unit and how they may combine/interact to lead to the multifactorial nature of APOs.

\section{Biological Mechanisms Leading to Adverse Pregnancy Outcomes}

3.1. Oxidative Stress. Aptly known as "The Oxygen Paradox," oxygen is both essential and toxic to the multicellular aerobic organisms whose very evolution was dependent on leveraging this anaerobic waste by-product into a higher energy producing advantage [167]. Observed in all mammals, a steep oxygen tension gradient from $20 \%$ in our atmosphere to $3-4 \%$ oxygen concentration in most internal tissues is the primary defense against oxidative damage. Secondary and tertiary layers of protection include antioxidant defenses as well as damage removal, repair, and apoptotic response systems [168, 169]. These genetically adaptive responses are upregulated in the presence of reactive oxygen species (ROS) generated as natural by-products of cellular aerobic metabolism and exposure to various toxins. Oxidative stress occurs when there is an imbalance between pro- and antioxidant capacity.

For example, superoxide is the most common intracellular ROS in mammals. It is produced by the mitochondria as a metabolic by-product but also from the metabolism of various growth factors, drugs, and toxins by oxidizing enzymes such as NADPH-oxidase and cytochrome P450 (CYP450). Superoxide is reduced by superoxide dismutase (SOD) into 


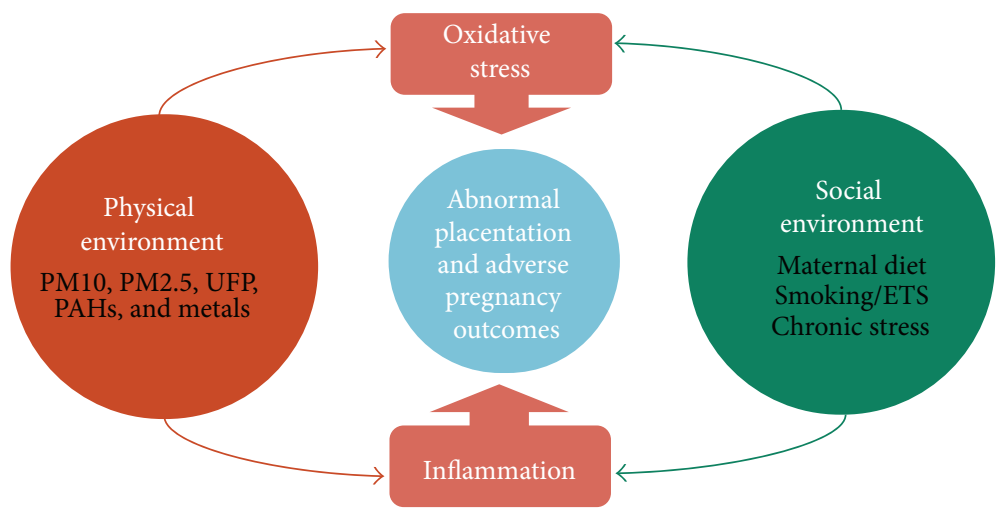

Figure 1: A conceptual framework of the shared mechanisms of socioeconomic determinants and particulate air pollution exposure contributing to adverse pregnancy outcomes. The physical environment (orange) consisting of particulate air pollution and the social environment (green) consisting of community and individual-level social factors/stressors converge to affect the fetal-placental environment (blue) via oxidative stress and inflammatory mechanisms potentially leading to adverse pregnancy outcomes.

hydrogen peroxide $\left(\mathrm{H}_{2} \mathrm{O}_{2}\right)$ which is then further reduced into water by glutathione peroxidase $(\mathrm{GPx})$ and catalase. Under normal physiological conditions $\mathrm{H}_{2} \mathrm{O}_{2}$ acts as intracellular secondary messengers; however, it's accumulation along with superoxide can react with free iron ions or nitric oxide to form highly toxic hydroxyl $\left(\mathrm{OH}^{*}\right)$ or peroxynitrite $\left(\mathrm{ONOO}^{-}\right)$ ions, respectively $[70,168]$. Free iron is a common metal found absorbed to PM, and the antioxidant heme oxygenase1 (HO-1) facilitates its conjugation and removal through the increased availability of ferritin thereby preventing the formation of reactive hydroxyl molecules [92, 170-172]. Deficiencies in HO-1 have been associated with several APOs such as recurrent miscarriage, FGR, and preeclampsia [171, 172].

Common antioxidants include enzymatic (e.g., SOD, GPx, catalase, and HO-1) and nonenzymatic compounds (e.g., vitamin $\mathrm{C}$ and $\mathrm{E}$, glutathione, $\beta$-carotene, and ubiquinone) [118]. Genetic polymorphisms and/or micronutrient deficiencies in antioxidant enzymes precursors can impair antioxidant capacity, while chronic exposure to toxicants, psychosocial stress, bacteria, viruses, and other inducers of inflammation can foster prooxidant burden [70,77, 118, 172]. Oxidative stress is unavoidable; however, under optimal conditions the presence of ROS leads to homeostatic adaptation and are safely removed. Failure to effectively manage oxidative stress can result in altered cellular function as excess ROS degrade lipids, proteins, and DNA potentially initiating pathological processes. Refer to [168] for an extensive review on the role of cellular ROS in pregnancy outcomes.

3.2. Inflammation and Immunologic Alterations. It is well recognized that the maternal immune system plays a central role throughout the entire pregnancy, from preimplantation to parturition, and is influenced by the inflammatory response of the mother to her environment as well as to her partner. Alternative to previously hypothesized [173], the maternal immune system is not passive or suppressed during implantation and development of the semiallogeneic placenta and fetus. Rather, it exerts executive influence on the establishment and progression of the pregnancy as an immunemediated quality control mechanism to maximize maternal and offspring health $[44,173]$. This is achieved by favouring pro- or anti-inflammatory environments at different times during pregnancy for different purposes. For instance, implantation, initial placentation, and parturition are characterized by a proinflammatory environment whereas an antiinflammatory state prevails for most of midgestation [174]. The favoured localized immunological response however is highly modified by the infectious, inflammatory, stress, nutritional, and metabolic status of the individual and thus can be influenced by environmental agents such as PM [175177] and/or available coping, social, and nutritional resources $[44,128,164,178]$. Therefore, inflammation is believed to be one pathway involved in both PM and SES-mediated APOs.

Chronic and acute inflammation is a complex response process mediated by a real or perceived attack from foreign substances. The innate immune response is the rapid automatic response to externally originating (exogenous) substances such as pathogens, but also from internal (endogenous) danger signals including products of trauma, ischemia, necrosis, or oxidative stress [179]. The response includes the release of proinflammatory signaling cytokine proteins such as interleukins IL- $1 \beta$, IL- 6 , and tumour necrosis factor (TNF$\alpha$ ) which serve to recruit neutrophils to affected tissues. However, the recruited neutrophils release ROS and hydrolytic proinflammatory enzymes (inducible nitric oxide synthase (iNOS), cyclooxygenase (COX-2), and prostaglandins (PG$\left.\mathrm{E}_{2}\right)$ ) which disturb normal cells in addition to affected tissues. This in turn leads to increased ROS and oxidative stress $[180,181]$. The placenta plays a role at the maternalfetal interface as the main producer of endocrine steroid and protein hormones as well as the immunologic barrier between mother and fetus which positively interact for the success of the pregnancy $[44,173]$. This is achieved through a nonlinear series of positive and negative feedback pathways with the stimulation or suppression of molecules with pro- and anti-immunosuppressant properties (interleukins, galectins, placental growth factor, and human chorionic gonadotropin (hCG)) [182-184]. The production of these cytokines, chemokines, and other immune-regulatory agents mediates the coordination, migration, and function of several 


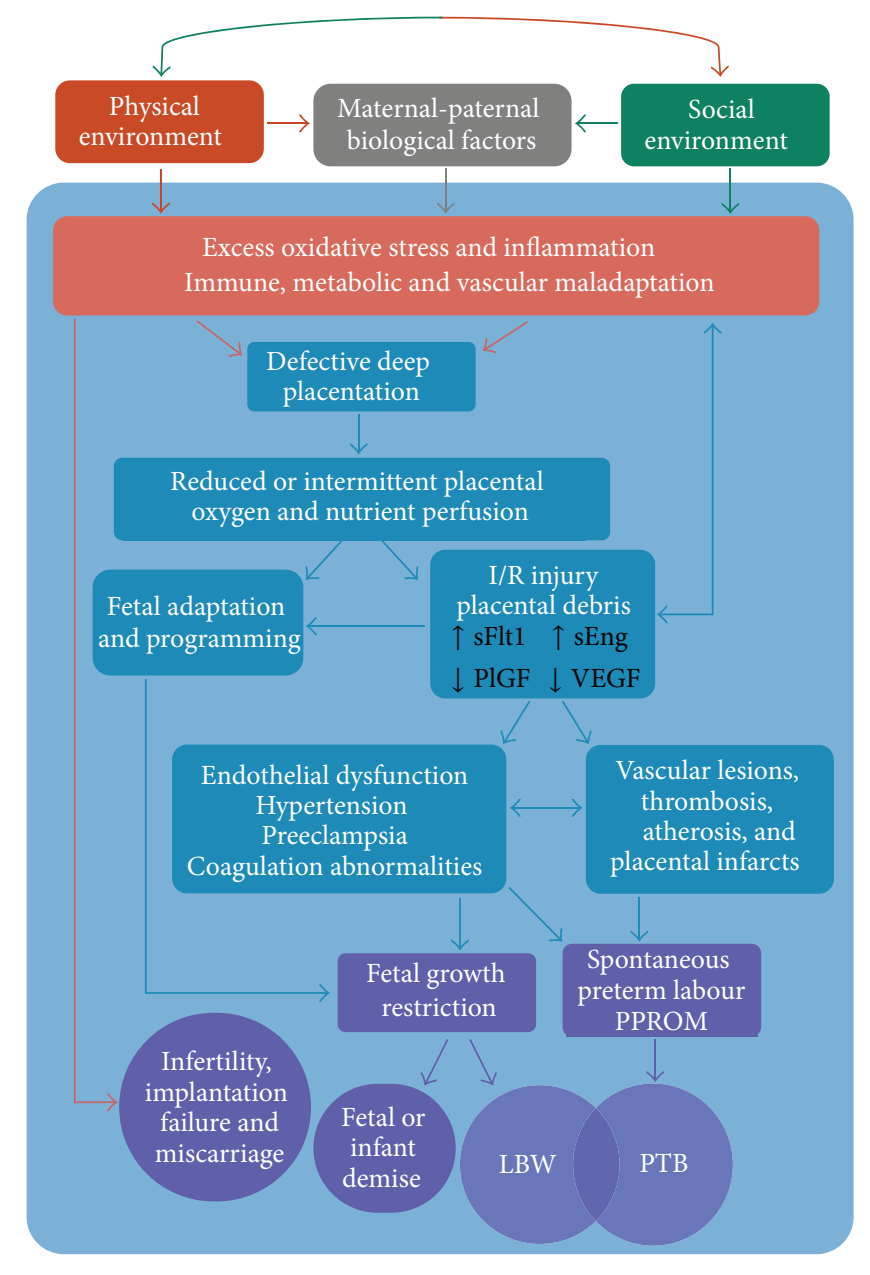

FIGURE 2: Proposed pathways contributing to adverse pregnancy outcomes. The co-presence of maternal and paternal biological factors can result in protection or increased susceptibility to the interaction with the physical and social environments. Cumulative negative exposures early in pregnancy resulting in excess oxidative stress and inflammation may cause a cascade of events leading to defective deep placentation. Depending on the degree of severity, the reduced transplacental perfusion can result in various pathologies associated with a range of obstetric complications and outcomes $[60,61,69,70]$.

maternal immune cells (e.g., uterine natural killer cells $(\mathrm{uNK})$ ) that participate in early pregnancy events such as endometrial receptivity of embryo implantation, tissue remodeling, immune tolerance, and vascular adaptation to invading placental trophoblast cells [44, 182-184]. Interference or aberrant production/secretion of these substances by various stressors including infection, toxins, and those acting through the HPA-axis may result in the impaired maternal immune response leading to the hallmark DDP syndrome complications described above (early pregnancy loss, PIH/PE, PROM, FGR, and premature labour, Figure 2) [44, 61, 69, 134, 175, 185-187].

\subsection{Mechanisms of Oxidative Stress and Inflammation Involved in Adverse Perinatal Outcomes}

3.3.1. Impaired Fertility and (Recurrent) Miscarriage. Due to immortal time bias, miscarriage is not easily measured in population or cohort studies without careful design methodologies [188, 189]; however, associations between infertility and air pollution have been made $[190,191]$. Oxidative stress has shown to have a direct effect on fertility and embryo development. For example, obese mice showed increased ROS synthesis and oxidation in oocytes with a reduced ability of zygotes to develop to the blastocyst stage providing evidence that impaired cellular antioxidant capacity can limit successful ovulation and fertilization [118]. Dividing mitotic cells are particularly sensitive to oxidative damage and are shown to enter a transient growth-arrested state as a protective mechanism until the stress has passed. Thus, severe or chronic oxidative stress may hamper cell division or cause cellular necrosis reducing or terminating embryo viability $[72,169]$. Alternatively, an exaggerated inflammatory state via a viral, toxic, and/or allostatic load could lead to a maternal immune maladaptation to conception restricting trophoblast stem cell accumulation in the early embryo responsible for the production of hormones that enables successful implantation (Figure 2) [44, 72].

Oxidative stress is implicated in first trimester miscarriage from premature placental perfusion of maternal oxygenated blood and accompanying ROS into the early embryonic environment [192]. Early embryo development occurs in a low oxygen state, and it is not until the tenth to twelfth week of gestation that maternal blood begins to gradually infiltrate the intervillous space of the yet fully developed placenta. The limited oxygen environment is thought to act as a protective mechanism against the deleterious and teratogenic effects of ROS on early stem cells at a time of extensive cell division $[64,138]$. This early hypoxic environment also plays a vital physiological role in placental cell type differentiation switching from proliferative villous cytotrophoblasts into invasive extravillous trophoblasts (EVT) important in spiral artery remodeling [193]. At the end of the first trimester, oxygen tension rises sharply which coincides with the infusion of oxygenated maternal blood into the placenta and triggers an apoptotic cascade that serves to establish the definitive discoid placenta. However, in $70 \%$ of early miscarriage cases EVT invasion is insufficient allowing for the premature onset of maternal intraplacental circulation and its consequential burst of ROS on the conceptus [70, 192]. Severe cases may result in pregnancy failure while more modest cases may initiate fetal-maternal adaption to impaired spiral artery remodeling leading to the DDP pathology and further complications later in pregnancy such as FGR and PIH/PE (Figure 2) [69, 70, 193].

\subsubsection{Pregnancy Induced Hypertension, Preeclampsia, and} Prelabour Rupture of Membranes. While oxidative stress and inflammation are conditions of normal pregnancy, they are consistently elevated in cases of PIH/PE and central in its pathology. PIH/PE stems from a defect in early trophoblast invasion insufficient to fully convert the spiral arteries into 
low-resistance channels $[68,194]$. The retention of smooth muscle cells remains active to circulating vasoconstricting agents such as stress hormones (e.g., glucocorticoids) and other stimulants. The diminished and intermittent perfusion of maternal blood into the intravillous space produces transient hypoxia resulting in a chronic ischaemia-reperfusion (I/R) type injury. This further provokes ROS synthesis and excess shedding of placental microvesicles which have proinflammatory, antiangiogenic, and procoagulant activity initiating endothelial dysfunction [68-70]. Elevated circulating levels of placental debris and ROS biomarkers in the placental tissues of preeclamptic women are well documented $[68,179$, 194]. Similarly, PROM can be considered part of the DDP syndrome but may represent a phenotype resulting from a less severe DDP pathophysiology compared to preeclampsia $[61,62]$. Excess oxidative stress arising from multiple causes (infection, inflammation, smoking, and cocaine use) has been implicated in PROM in addition to its role in DDP [70]. Both $\mathrm{PIH} / \mathrm{PE}$ and PROM are leading causes of preterm birth, while $\mathrm{PIH} / \mathrm{PE}$ is a major risk factor for FGR (Figure 2) [69]. Deficiencies in HO-1 have been associated with preeclampsia as well as morphological changes in the placenta and elevations in maternal blood pressure. The bioactive HO-1 metabolites $\mathrm{CO}$ and bilirubin may protect against preeclampsia through their vasodilatory properties and the suppression of the antiangiogenic factor sFlt, respectively $[171,172]$.

3.3.3. Fetal Growth Restriction. FGR has many causes however often arises from placental insufficiency due to compromised supply of oxygen and nutrients to the fetus which may have both short- and long-term health consequences on the offspring [51, 82, 195]. FGR is strongly associated with early onset or more severe cases of preeclampsia, and there is a clear etiological link between FGR and DDP as it involves abnormal placentation and reduced uteroplacental blood flow (Figure 2) [62, 70]. Alternatively, perturbed calcium homeostasis can induce chronic low-level stress within the endoplasmic reticulum leading to suppressed protein synthesis and a reduced growth trajectory of the placenta [70]. Cadmium, an environmental toxin and highly present in cigarette smoke, is a major antagonist of cellular calcium activities (transport, uptake, and binding) as well as in the transfer of other nutrients and zinc homeostasis within the placenta $[134,185,196]$. Furthermore, cadmium is a known endocrine disruptor shown to impair hormone synthesis in the placenta including progesterone and leptin, important hormones in early pregnancy $[49,175,186]$. Both smoking and air pollution exposure were associated with lower birth weights along with low blood progesterone levels and high placental cadmium concentrations compared to a non-exposed control group [135].

3.3.4. Spontaneous Preterm Labour and Birth. Inflammation is proposed as one potential mechanism leading to spontaneous preterm labour, both with intact membranes or PROM [177]. The classification of patients who deliver preterm can be categorized into two non-mutually exclusive clusters: those who present with inflammatory lesions (e.g., acute chorioamnionitis and funisitis) and those with vascular lesions who tend to have longer gestational periods [61]. The consequence of uteroplacental ischemia as a result of such lesions will depend on the severity, the timing, and duration of the insult. While a complete blockage of uterine arteries will lead to fetal death, less severe ischemia will result in different clinical phenotypes as a result of adaptive mechanisms for fetal survival. This may include fetal growth restriction if chronic underperfusion of oxygen and nutrients persists, the onset of maternal hypertension to sustain or increase uterine blood flow, and/or the initiation of preterm labour as a maternal/fetal adaptation to continued growth restriction in utero (Figure 2) [61, 197]. Cardiovascular lesions indicating thrombosis and atherosis are shown to be indirectly caused by exposure to $\mathrm{PM}_{2.5}$ and UFPs via inflammatory and/or oxidative injury [97].

\section{The Physical and Social Environments and Their Relation to Adverse Perinatal Outcomes}

4.1. PM-Induced Oxidative Stress and Inflammatory Mechanisms. Exposure to $\mathrm{PM}_{2.5}$ and its constituents, including PAHs and metals, induce oxidative stress and inflammation in many biological systems through various means (Figure 3) $[48,77-79,97,176,177,198]$. One method is the direct generation of ROS from free radicals and oxidants on particle surfaces including soluble transition metals such as iron, copper, chromium, and vanadium. As mentioned above, free iron can react with available superoxide or hydrogen peroxide to form highly reactive hydroxyl radicals $[70,77]$. PAHs and other organic molecules absorbed to $\mathrm{PM}_{2.5}$ and UFPs may account for a large proportion of their oxidative potential due to their ability to enter the cell and disrupt the mitochondria [79]. Altered function of mitochondria may produce excess quantities of NADPH-oxidase which in turn generates large amounts of cellular superoxide, a process already in overdrive throughout pregnancy but particularly in the first trimester $[70,77]$. Interpolated ambient $\mathrm{PM}_{10}$ exposure was shown to be negatively associated with the number of placental mitochondrial DNA, a molecular marker of mitochondrial disruption and inflammation. This association was reversed with increasing distance from major roads, a proxy for trafficrelated air pollution [48].

Alternatively, PM/PAH mediated oxidative stress can be induced by the activation of the inflammation system. Immunotoxic compounds can promote the release of proinflammatory cytokines, TNF- $\alpha$, and COX-2, which in turn act in a positive feedback loop to generate more ROS and oxidative stress [77]. For example, modelled $\mathrm{PM}_{10}$ and $\mathrm{PM}_{2.5}$ exposure has been positively associated with elevated C-reactive protein (CRP) levels, a biomarker of systemic inflammation, in both maternal first trimester blood and fetal cord blood in a dose-dependent manner [176, 200]. CRP is produced in the liver and part of the acutephase response released during inflammatory reactions from cytokines produced in the lungs. Raised CRP is a risk factor for cardiovascular disease as a marker of unstable atheromatous plagues leading to thrombosis and ischemic 


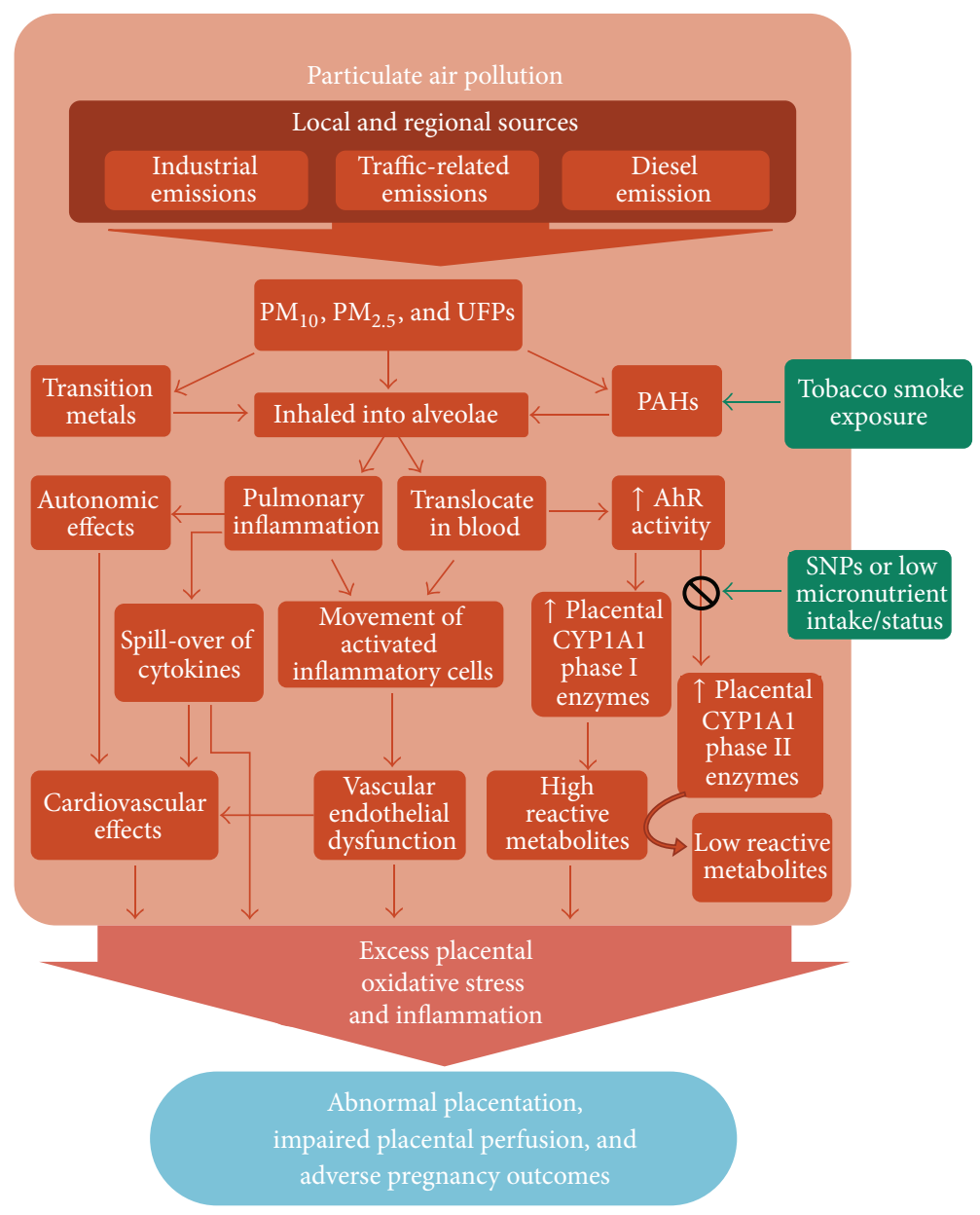

FIGURE 3: Proposed pathways of particulate air pollution contributing to oxidative stress and inflammation leading to adverse pregnancy outcomes. Exposure to PM and its associated constituents of transition metals, PAHs, and other organic molecules affect the cardiovascular and metabolic systems which are highly active throughout pregnancy. For example, detoxification of PAHs and other organic toxins activate AhR signalling resulting in additional oxidative stress if antioxidant defenses are limited or impaired $[55,79,98,108,109,199]$.

events [97]. Exposure to diesel exhaust in healthy human volunteers resulted in pulmonary inflammation in addition to systemic inflammation, prothrombotic changes, and other cardiovascular effects consequent of proinflammatory events [99, 201]. This hyper proinflammatory state, along with oxidative stress, is hypothesized to contribute to several APOs $[69,70,174,181,202]$.

Indirectly, the cellular detoxification of PAHs can induce oxidative stress and cytotoxicity by forming potent ROS metabolite by-products. Specifically, PAHs and other organic xenobiotics (notably PCBs and dioxins) are detoxified by the cytochrome P-450 (CYP) superfamily of Phase I and Phase II metabolizing enzymes. The expression of these enzymes is highly modulated by genetic polymorphisms, steroid/sex hormones such as glucocorticoids, insulin, estrogens, and progesterone, and micronutrient/dietary deficiencies [74, 75, 128, 203, 204]. Furthermore, hypoxia, infection, and inflammation are shown, in general, to downregulate CYP enzymes which may affect the clearance and bioavailability of growth factors, hormones, drugs, and toxins [203, 205]. CYP has numerous isoforms which are expressed in many tissues especially the liver. CYP1A1 is the only isoform also significantly expressed in the placenta throughout pregnancy responsible for metabolizing steroid/sex hormones, growth factors, and fatty acids in addition to toxins [75]. These exogenous and endogenous substances act as ligands to activate the aryl hydrocarbon receptor (AhR), a transcription factor that mediates the biotransformation of such ligands (PAHs, estradiol, etc.) into more polar and bioavailable metabolites by upregulating CYP enzymes. However, certain metabolites of PAHs (e.g., o-quinones, arene oxide, and diol epoxide) bind to DNA, RNA, and protein macromolecules to form toxic adducts that disrupt DNA replication and are considered mutagenic [72, 75]. Such DNA adducts have been found in newborn cord-blood positively correlated with maternal exposure to PAHs [50]. PAHs have also shown to significantly decrease the accumulation of trophoblast stem cells in the early placenta thereby limiting their differentiation into other cell types vital for hormone synthesis and ongoing placental development, a process that could contribute to DDP [72]. Direct prenatal exposure to airborne PAHs has been associated with FGR with an increased exposure-related 
risk in the first trimester [206, 207]. Secondary (Phase II) metabolizing enzymes are required to further detoxify reactive $\mathrm{PAH}$-metabolites in which their inefficient clearance results in prolonged exposure leading to sustained cytotoxicity and mutagenicity. Phase II enzymes include glutathione stransferases (GSTs), UDP-glucuronosyltransferases (UGTs), $\mathrm{NAD}(\mathrm{P}) \mathrm{H}$-dependent quinone oxidoreductase-1 (NQO1), and aldehyde dehydrogenase-3 (ALDH3) [75, 205].

4.2. Maternal Diet and Micronutrient Intake. Adequate diet and micronutrient status provides resilience against oxidative stress and inflammation caused by various exposures including air pollution, allostatic stress, infection, and smoking (Figure 4) [55, 118, 128, 129, 131, 143]. Many micronutrients such as essential trace metals are vital cofactors in several antioxidant enzyme systems. For example, copper and zinc are necessary in the production of SOD. Similarly, selenium and its incorporation into the amino acid selenocysteine are required for the functionality of all selenoenzymes, including GPx and GST. Thus, selenium is essential in several aspects of human health, particularly conditions involving oxidative stress and inflammation such as CVD, immune function, cancer, and reproduction, but also thyroid regulation and brain diseases [208, 209].

ROS may have direct effects on oocyte quality and appears to be modulated by dietary antioxidant supplements [118]. Women who are obese tend to have higher rates of infertility that correlate with increased levels of oxidative stress biomarkers in their blood as excess glucose availability leads to higher mitochondrial ROS synthesis [70, 118]. Selenium deficiency and corresponding reduced GPx activity has been documented in cases of recurrent miscarriage and spontaneous abortions [210-212] and has also been associated with preeclampsia and preterm birth [213, 214]. However, given the supposed role of oxidative stress in preeclampsia, treatment with certain antioxidants (notably vitamins $\mathrm{C}$ and $\mathrm{E}$ ) has not produced reliable preventative results in experimental trials [69]. One hypothesis is that inappropriate antioxidant regiment and/or administration too late in gestation are responsible and new therapeutic candidates include melatonin and selenium [118]. Interestingly, national programs in Finland and New Zealand fortifying food with selenium have been associated with a significant reduction in the rate of preeclampsia [215].

Oxidative stress negatively affects the placental transport of amino acids and glucose [45]. Furthermore, fatty acids and low density lipid (LDL) cholesterols necessary for the placental synthesis of oestrogens and progesterone are particularly vulnerable to oxidative injury [216]. Regulation of placental nutrient transport is controlled by several different mechanism, including imprinted genes, placental signaling pathways, various cytokines, and hormones such as insulin, leptin, glucocorticoids, and oestrogens (for review see [45]). The major placental transfer mechanisms include simple diffusion of lipophilic substances (e.g., oxygen, $\mathrm{CO}_{2}$, fatty acids, steroids, fat soluble vitamins, and anesthetic gases), restricted diffusion of hydrophilic substances, facilitated diffusion via a membrane bound carrier (e.g., glucose and other carbohydrates), and active transport which requires

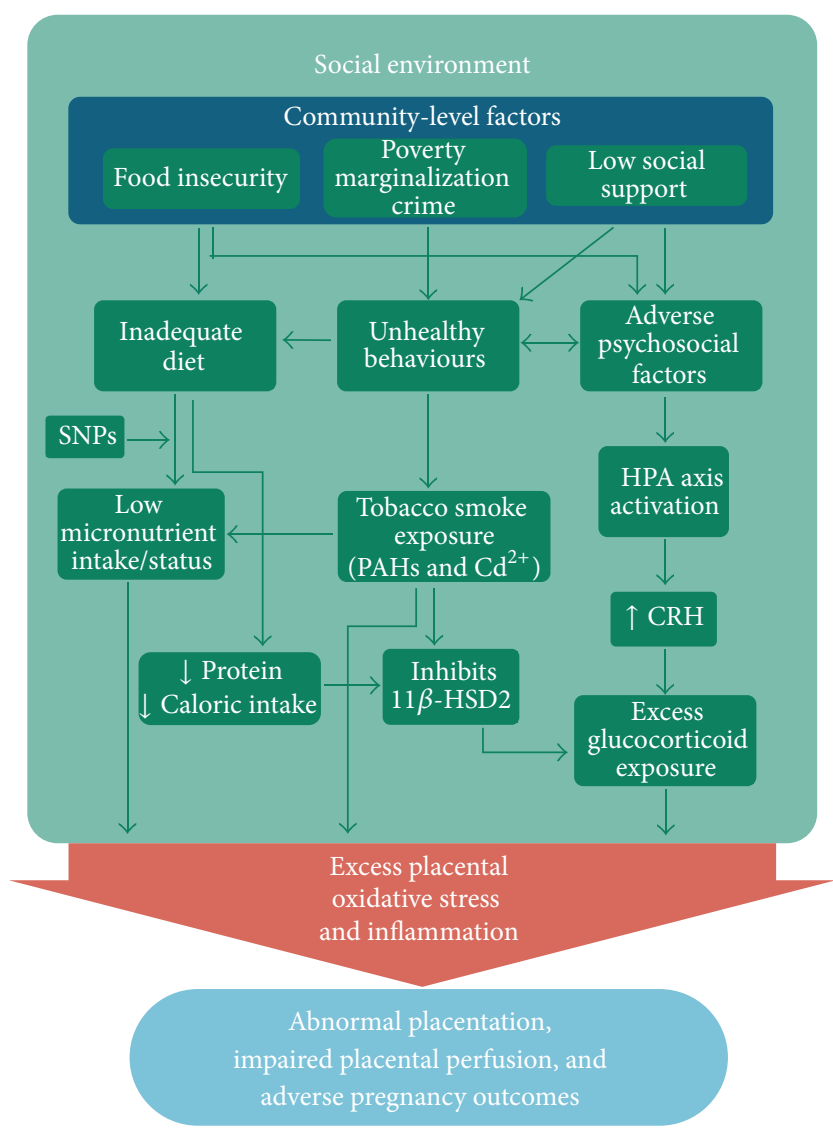

Figure 4: Proposed pathways of how the social environment interacts to produce excess systemic and placental oxidative stress and inflammation leading to adverse pregnancy outcomes. The pregnant woman is nested within and influenced by neighbourhood/community-level factors which can exasperate or buffer the individual-level biological and behavioural factors $[24,26$, $54,128,224,225]$.

energy (e.g., amino acids, iron, calcium, and other divalent cations) $[45,217]$. Placental physiology, including spiral artery remodeling and placental villous surface area are major determinants dictating placental transport capacity, and the degree of placental developmental disruption correlates with the severity of obstetrical complications associated with DDP $[51,62]$.

Nutrition and diet can influence perinatal health in opposing directions (i.e., it can be an antagonist or agonist). Poor/undernutrition such as high fat/calorie dense food and low micronutrient intake is more prevalent among women from low SES backgrounds which may partly explain higher rates of some APOs [12,139-142]. On the other hand, good nutrition and supplemental vitamin intake is capable of reducing the toxicity of everyday environmental stressors as well as preventing certain APOs and congenital anomalies as shown with the successful reduction of neural tube defects with folic acid $[128,143,218]$. Nutritional and/or genetically induced deficiencies in folate and vitamins B6 and B12 can disrupt the homocysteine-to-methionine pathway resulting in hyperhomocysteinemia (HHC), a known risk factor of 
cardiovascular morbidities (thrombosis, lesions, and infarcts) and markers of oxidative stress $[54,119,219,220]$. HHC may similarly affect the highly vascularized placenta and has been associated with decidual vasculopathy and preterm birth $[54,120]$. Omega-3 fatty acids abundant from eating salmon were shown to improve markers of oxidative stress [221], which may impart neurodevelopmental resilience against stressors [222, 223]. Dietary phytophenols from fruits, vegetables, herbs, and spices have shown to have antioxidant and anti-inflammatory properties capable of reducing infectioninduced inflammatory and contractile pathways in human gestational tissues [129]. Significant differences in pregnancy outcomes between Dominicans and African Americans both exposed to similar levels of PAHs in New York city neighbourhoods were thought to be due to healthful dietary/cultural practices in the Dominican immigrant population [206].

\subsection{Maternal Smoking and Environmental Tobacco Smoke} (ETS) Exposure. Maternal smoking during pregnancy and exposure to ETS remain to be two modifiable risk factors with the greatest potential for beneficial interventions (Figure 4). Their association with numerous APOs including congenital anomalies is well documented [127, 144-146], as have their associated prevalence with indicators of low SES and other socially patterned risk factors [147-149]. The mechanisms involved leading to APOs have been well reviewed [132, 134]; however, it is notable that the two main toxins present in tobacco smoke can also be absorbed to $\mathrm{PM}_{2.5}$ (PAHs more so than cadmium). Cadmium (Cd) exposure readily interferes with the active transport of essential minerals to the fetus, particularly zinc and calcium [46, 135, 196, 226-228]. Cadmium and lead $(\mathrm{Pb})$ exposure has also been shown to reduce glycogen concentrations thereby potentially limiting available glucose to the fetus [229]. Cadmium has shown to disrupt placental leptin synthesis, a hormone with several vital functions including placental angiogenesis, immunomodulation, amino acid and fatty acid transport, as well as fetal pancreatic development important in the regulation of insulin-like growth factors and fetal body fat accumulation $[49,51]$. Finally, synergistic effects in the generation of oxidative hydroxyl radicals have been observed between tobacco smoke and both ambient $\mathrm{PM}_{2.5}$ and diesel exhaust particles specifically [35]. Interestingly, the counterintuitive association between smoking and lower risk of preeclampsia was recently shown to vary according to the timing and intensity of smoking [230]. It is possible that the increased exposure to $\mathrm{CO}$ from smoking in late gestation acts as a vasodilator and at the same time inhibits the release of sFlt-1, a hallmark antiangiogenic factor implicated in the endothelial dysfunction present in preeclampsia [115, 230].

4.4. Allostatic Stress and Glucocorticoid Exposure. Reviewed elsewhere [163], the brain is the primary target and mediating organ through which SES-related stress pathways are translated to other body systems via the hypothalamic-pituitaryadrenal (HPA) axis. The HPA-axis is actively involved in several biological systems, including the cardiovascular, metabolic, immunological, and endocrinal effects in both mother and fetus to promote allostatic adaptation [165, 231]. Here, the neuroendocrine hormones of the HPA axis, corticotrophin releasing hormone $(\mathrm{CRH})$, adrenocorticotropic hormone (ACTH), and glucocorticoids (GC), respectively, coordinate the biological response via feedback loops. The human placenta is also capable of releasing $\mathrm{CRH}$ and other neuropeptides which interact with the HPA axis to regulate the maternal stress response as well as other normal pregnancy functions [47]. Proper levels of in utero glucocorticoids are essential for successful embryo implantation, fetal organ maturation, and the initiation of labour with glucocorticoid levels gradually increasing over the course of gestation. Normally, levels of maternal cortisol rise sharply in the third trimester causing the release of placental $\mathrm{CRH}$ in a positive adrenal-placental feedback loop. Placental CRH stimulates fetal cortisol secretion which in turn suppresses placental progesterone and activates the release of prostaglandins and oxytocin to promote uterine contractions $[47,232]$. However, early and increased levels of fetal glucocorticoids can impair growth and predispose to adult-onset diseases $[136,233$, 234]. The placental enzyme $11 \beta$-hydroxysteroid dehydrogenase type $2(11 \beta$-HSD2) protects the fetus from excess endogenous glucocorticoids by converting active cortisol into inactive cortisone. $11 \beta$-HSD2 is hormonally regulated making it susceptible to endocrine disruption from chemical and nonchemical stressors such as maternal anxiety, inflammation, infection, cadmium exposure, and low caloric intake $[136,138,224,235,236]$. Placental hypoxia associated with $\mathrm{PIH} / \mathrm{PE}$ has been shown to suppress $11 \beta$-HSD2 activity which may be an adaptive response to counteract compromised fetal growth by allowing more cortisol to reach the fetus for organ development. Low concentrations/activities of $11 \beta$-HSD2 and high levels of cortisol have been associated with PTB and FGR [136, 237, 238], two outcomes also associated with poor maternal psychosocial/mental health [233, 234, 239].

Factors affecting $11 \beta$-HSD2 activity that are associated with low SES include allostatic overload leading to the excess production of glucocorticoids that can overwhelm the fetal protective mechanism (Figure 4) [136, 231, 240]. Indirectly, allostatic load is capable of disrupting the metabolic system leading to impaired glucose tolerance, insulin resistance, diabetes, and/or obesity, all of which are risk factors for various APOs [138, 165, 231]. General maternal undernutrition and/or a low dietary protein intake has been shown to impair placental glucose transport and inhibit $11 \beta$-HSD2 activity in pregnant rats leading to FGR, indicating a possible mechanism through poor diet [224, 241]. Additionally, cadmium has also shown to inhibit $11 \beta$-HSD2 activity in both human and rodent placentas [225], and prenatal cadmium exposure has been shown to increase fetal corticosterone concentrations in rats which resulted in reduced birth weights [236]. This suggests a possible mechanism from active or passive tobacco smoke exposure or ambient $\mathrm{PM}_{2.5}$ exposure $[135,242,243]$. Collectively, it is possible for the cumulative exposures of $\mathrm{PM}_{2.5}$, smoking, ETS, poor dietary intake, and other SES-related factors to interact through the same $11 \beta$ HSD2 mechanism to increase the risk of impaired fetal growth (Figure 4). 


\section{Discussion}

The ubiquitous exposure to particulate air pollution and its constituents (e.g., PAHs and metals) is but one class of environmental contaminants that can act through oxidative stress, inflammation, and/or endocrine disruption to promote developmental toxicity and adverse perinatal health $[177,244,245]$. Summarized in Figure 2, a perturbed early in utero environment can lead to defective deep placentation resulting in a cascade of fetal-placental adaptive mechanisms contributing to a range of pregnancy complications and adverse outcomes [60]. Here the underlying biological, social, and physical risk factors likely intersect to produce excessive or atypical oxidative stress, inflammatory response, and biological antagonism to either initiate the defective deep placentation pathology and/or contribute to the severity of its phenotype. Socioeconomic disparities are known to confound the environmental exposure effects; however, they may also act as potential effect modifiers given their overlapping etiological mechanisms with $\mathrm{PM}_{2.5}$ exposure. While the traditional biomedical paradigm that views populations as a collection of independent individuals has yielded useful information regarding risk factors, elucidating the intersecting pathways involved in APOs will require placing individual biologic and behavioural determinants within the social and spatial context $[22,246]$. It is now well recognized that SES operates at multiple levels of organization, and neighbourhood or community-level factors can work to either ameliorate or exacerbate certain risk factors $[15,24-$ 26]. The healthy migrant paradox exemplifies these effects in which home country, education, and neighbourhood qualities combine to modify the expected perinatal outcomes often observed with low income households [161, 247].

The SES risk factors that overlap or interact with the PMmediated mechanisms include smoking, nutrition, and psychosocial stress acting through the HPA-axis and allostatic load. Given this knowledge, interventions aimed at ameliorating these factors may be the best way to counteract the negative influences of low SES and air pollution exposure on fetal development. Maternal smoking continues to be one of the most modifiable risk factors to lower the risk of APOs [134, 147]. Furthermore, maternal smoking also tends to interact negatively with nutrient intake and status [133, 248]. Smokers in general have poorer nutritional profiles than nonsmokers with both behavioural and biological factors independently accounting for the differences in micronutrients such as folate and essential vitamins and minerals [133, 248-250]. While smokers tend to have lower dietary nutrient intakes, they also have an accelerated requirement for micronutrients due to increased inflammatory cell turnover caused by the oxidative stress of smoking, an effect more pronounced among heavy and long-time smokers [248]. These interacting effects of smoking and nutrition are further compounded by their association with other indicators of low SES such as low education and income contributing to allostatic load [139, 251]. Nutrient intake may be ameliorative after an insult has occurred as shown in rat models of fetal alcohol syndrome where an omega-3 fatty acid enriched diet reversed the cellular effects of prenatal ethanol exposure on the fetal brain [222].
Therefore with respect to policy interventions, nutrition in the form of improved food security and micronutrient intake may serve to counteract the negative influences of both low SES and air pollution exposure [252-257].

The complex mixture of particulate air pollution, especially $\mathrm{PM}_{2.5}$ and UFPs which includes absorbed PAHs and various metals, also emerges as an important target for risk reduction and management. The deserved scrutiny stems from their ubiquity in the environment, the myriad of emission sources, and their established association with APOs $[88,98,258]$. The pervasiveness of $\mathrm{PM}_{2.5}$ and UFPs in the environment means that a high proportion of people are exposed resulting in a high etiological fraction. Therefore, even a modest reduction in exposure will have a large population effect with reduction of the societal costs of APOs [259]. Notably, their sources are primarily local, such as vehicle emissions and industrial land-use. This makes them modifiable risk factors that can be addressed at the municipal and provincial/state level with better urban planning to reduce vehicle traffic, increasing access to green-space and enforcing air quality regulations [260-263].

Not unlike the accumulation of evidence on smoking and health outcomes or that of air pollution on cardiovascular and pulmonary health [264], the epidemiological and toxicological research over the past two decades has established a consistent dose-response association with high biological specificity, temporality, and plausibility $[3,55,177]$. Taken in concert, these characteristics and further corroborating research should lend strength for evidence-based policy for intervention strategies targeting high risk areas in order to reduce the environmental burden of disease attributed to particulate air pollution $[98,265,266]$.

\section{Conclusion}

Adverse pregnancy outcomes such as fetal growth restriction and preterm birth are a public health priority of global importance. We have brought together the multidisciplinary literature on the current state of evidence linking the physical and social environment to specific adverse pregnancy outcomes. The evidence suggests that various exposures, whether socially or environmentally determined, may be interpreted by the fetoplacental unit in similar ways resulting in a common pathological foundation for adverse outcomes, namely, deficient deep placentation. Given this background, well planned future epidemiology studies using multilevel models exploring various biological effects of the social and physical environment will have the potential to provide the evidence to establish crucial windows of fetal vulnerability with an aim to identify and mitigate modifiable risk factors.

\section{Acronyms}

AhR: Aryl hydrocarbon receptor

ACTH: Adrenocorticotropic hormone

APO: Adverse pregnancy/perinatal outcome

Cd: Cadmium 


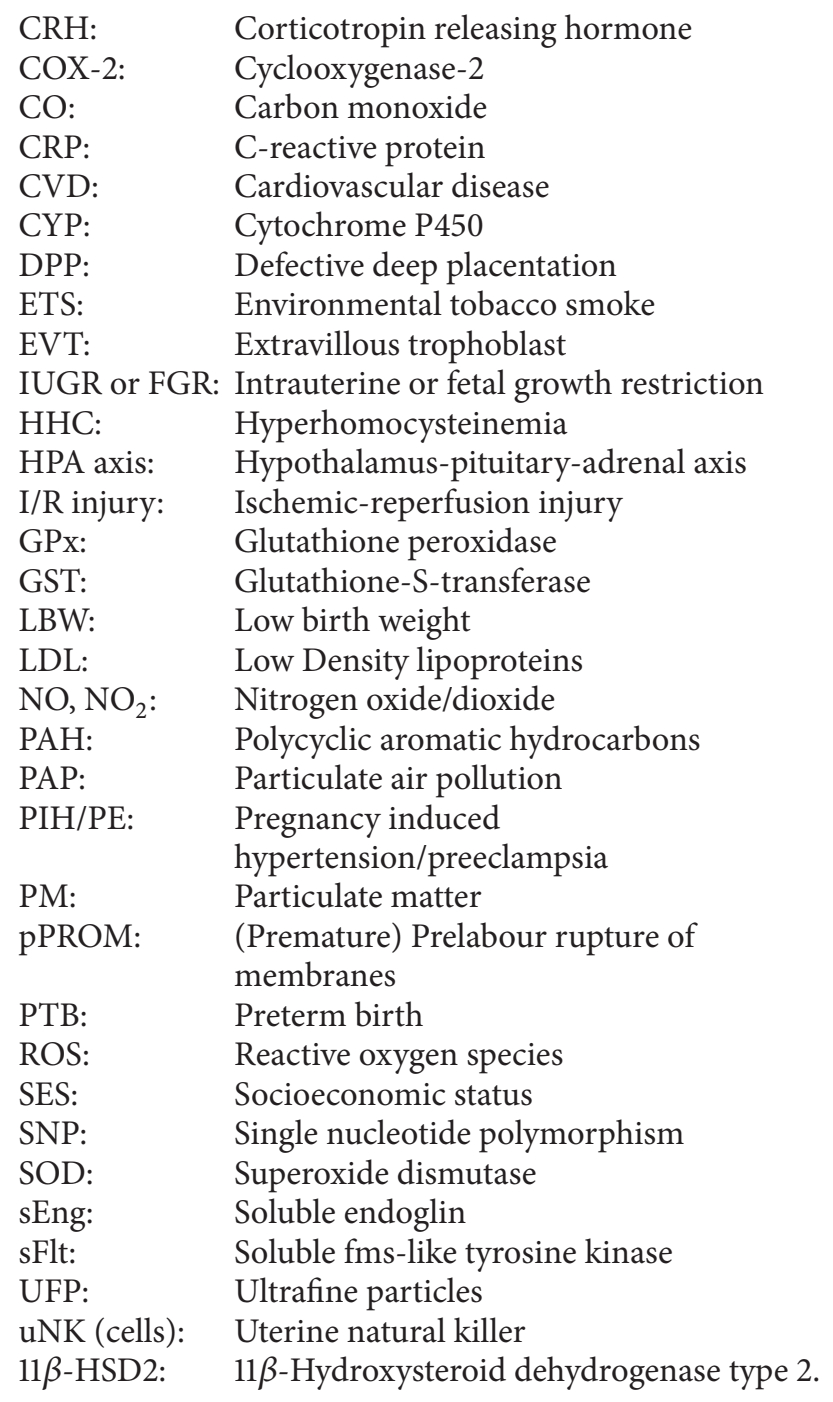

\section{Conflict of Interests}

The authors declare that they have no conflict of interests.

\section{Acknowledgments}

This research was funded by a Canadian Institute of Health Research Grant (IPH-98849). Dr. Arbour is also funded through a Michael Smith Foundation for Health Research Salary Award. Funders provided no role in the direction of this review paper.

\section{References}

[1] R. J. Šrám, B. Binková, J. Dejmek, and M. Bobak, "Ambient air pollution and pregnancy outcomes: a review of the literature," Environmental Health Perspectives, vol. 113, no. 4, pp. 375-382, 2005.

[2] P. S. Shah and T. Balkhair, "Air pollution and birth outcomes: a systematic review," Environment International, vol. 37, no. 2, pp. 498-516, 2011.

[3] C. H. Backes, T. Nelin, M. W. Gorr, and L. E. Wold, "Early life exposure to air pollution: how bad is it?" Toxicology Letters, vol. 216, no. 1, pp. 47-53, 2013.
[4] M. Maisonet, A. Correa, D. Misra, and J. J. K. Jaakkola, "A review of the literature on the effects of ambient air pollution on fetal growth," Environmental Research, vol. 95, no. 1, pp. 106$115,2004$.

[5] C. Protano, T. Scalise, G. B. Orsi, and M. Vitali, "A systematic review of benzene exposure during pregnancy and adverse outcomes on intrauterine development and birth: still far from scientific evidence," Annali di Igiene, vol. 24, no. 6, pp. 451-463, 2012.

[6] C. Bosetti, M. J. Nieuwenhuijsen, S. Gallus, S. Cipriani, C. La Vecchia, and F. Parazzini, "Ambient particulate matter and preterm birth or birth weight: a review of the literature," Archives of Toxicology, vol. 84, no. 6, pp. 447-460, 2010.

[7] M. Lacasaña, A. Esplugues, and F. Ballester, "Exposure to ambient air pollution and prenatal and early childhood health effects," European Journal of Epidemiology, vol. 20, no. 2, pp. 183199, 2005.

[8] S. V. Glinianaia, J. Rankin, R. Bell, T. Pless-Mulloli, and D. Howel, "Particulate air pollution and fetal health: a systematic review of the epidemiologic evidence," Epidemiology, vol. 15, no. 1, pp. 36-45, 2004.

[9] P. Dadvand, J. Parker, M. L. Bell et al., "Maternal exposure to particulate air pollution and term birth weight: a multi-country evaluation of effect and heterogeneity," Environmental Health Perspectives, vol. 121, no. 3, pp. 267-373, 2013.

[10] J. D. Parker, K. C. Schoendorf, and J. L. Kiely, "Associations between measures of socioeconomic status and low birth weight, small for gestational age, and premature delivery in the United States," Annals of Epidemiology, vol. 4, no. 4, pp. 271-278, 1994.

[11] M. A. Wilcox, S. J. Smith, I. R. Johnson, P. V. Maynard, and C. E. Chilvers, "The effect of social deprivation on birthweight, excluding physiological and pathological effects," British Journal of Obstetrics and Gynaecology, vol. 102, no. 11, pp. 918-924, 1995.

[12] M. S. Kramer, L. Séguin, J. Lydon, and L. Goulet, "Socioeconomic disparities in pregnancy outcome: why do the poor fare so poorly?" Paediatric and Perinatal Epidemiology, vol. 14, no. 3, pp. 194-210, 2000.

[13] K. S. Joseph, R. M. Liston, L. Dodds, L. Dahlgren, and A. C. Allen, "Socioeconomic status and perinatal outcomes in a setting with universal access to essential health care services," CMAJ, vol. 177, no. 6, pp. 583-590, 2007.

[14] Z.-C. Luo, R. Wilkins, and M. S. Kramer, "Effect of neighbourhood income and maternal education on birth outcomes: a population-based study," Canadian Medical Association Journal, vol. 174, no. 10, pp. 1415-1420, 2006.

[15] P. Blumenshine, S. Egerter, C. J. Barclay, C. Cubbin, and P. Braveman, "Socioeconomic disparities in adverse birth outcomes: a systematic review," The American Journal of Preventive Medicine, vol. 39, no. 3, pp. 263-272, 2010.

[16] C. B. Petersen, L. H. Mortensen, C. S. Morgen et al., "Socioeconomic inequality in preterm birth: a comparative study of the Nordic countries from 1981 to 2000," Paediatric and Perinatal Epidemiology, vol. 23, no. 1, pp. 66-75, 2009.

[17] B. MacMahon, M. G. Kovar, and J. J. Feldman, "Infant mortality rates: socioeconomic factors. United States," Vital and Health Statistics Series 1: Programs and Collection Procedures, vol. 22, no. 14, pp. 1-68, 1972.

[18] A. Antonovsky, "Social class and the major cardiovascular diseases," Journal of Chronic Diseases, vol. 21, no. 2, pp. 65-106, 1968. 
[19] J. Cassel, "The contribution of the social environment to host resistance: the Fourth Wade Hampton Frost Lecture," The American Journal of Epidemiology, vol. 104, pp. 107-123, 1976.

[20] A. V. Diez-Roux, "Bringing context back into epidemiology: variables and fallacies in multilevel analysis," American Journal of Public Health, vol. 88, no. 2, pp. 216-222, 1998.

[21] K. E. Pickett and M. Pearl, "Multilevel analyses of neighbourhood socioeconomic context and health outcomes: a critical review," Journal of Epidemiology and Community Health, vol. 55, no. 2, pp. 111-122, 2001.

[22] A. J. McMichael, "Prisoners of the proximate: loosening the constraints on epidemiology in an age of change," American Journal of Epidemiology, vol. 149, no. 10, pp. 887-897, 1999.

[23] R. J. Sampson, J. D. Morenoff, and T. Gannon-Rowley, "Assessing "neighborhood effects": social processes and new directions in research," Annual Review of Sociology, vol. 28, pp. 443-478, 2002.

[24] G. Meng, M. E. Thompson, and G. B. Hall, "Pathways of neighbourhood-level socio-economic determinants of adverse birth outcomes," International Journal of Health Geographics, vol. 12, article 32, 2013.

[25] A. Metcalfe, P. Lail, W. A. Ghali, and R. S. Sauve, "The association between neighbourhoods and adverse birth outcomes: a systematic review and meta-analysis of multi-level studies," Paediatric and Perinatal Epidemiology, vol. 25, no. 3, pp. 236245, 2011.

[26] J. D. D. Morenoff, "Neighborhood mechanisms and the spatial dynamics of birth weight," American Journal of Sociology, vol. 108, no. 5, pp. 976-1017, 2003.

[27] J. E. Clougherty, C. A. Rossi, J. Lawrence et al., "Chronic social stress and susceptibility to concentrated ambient fine particles in rats," Environmental Health Perspectives, vol. 118, no. 6, pp. 769-775, 2010.

[28] M. C. Fortin, D. A. Cory-Slechta, P. Ohman-Strickland et al., "Increased lead biomarker levels are associated with changes in hormonal response to stress in occupationally exposed male participants," Environmental Health Perspectives, vol. 120, no. 2, pp. 278-283, 2012.

[29] D. A. Cory-Slechta, M. B. Virgolini, A. Rossi-George, M. Thiruchelvam, R. Lisek, and D. Weston, "Lifetime consequences of combined maternal lead and stress," Basic and Clinical Pharmacology and Toxicology, vol. 102, no. 2, pp. 218-227, 2008.

[30] B. B. Gump, J. Reihman, P. Stewart, E. Lonky, D. A. Granger, and K. A. Matthews, "Blood lead $(\mathrm{Pb})$ levels: further evidence for an environmental mechanism explaining the association between socioeconomic status and psychophysiological dysregulation in children," Health Psychology, vol. 28, no. 5, pp. 614-620, 2009.

[31] J. L. Bolton, N. C. Huff, S. H. Smith et al., "Maternal stress and effects of prenatal air pollution on offspring mental health outcomes in mice," Environmental Health Perspectives, vol. 121, no. 9, pp. 1075-1082, 2013.

[32] A. Kortenkamp, M. Faust, M. Scholze, and T. Backhaus, "Lowlevel exposure to multiple chemicals: reason for human health concerns?" Environmental Health Perspectives, vol. 115, supplement, pp. 106-114, 2007.

[33] D. O. Carpenter, K. Arcaro, and D. C. Spink, "Understanding the human health effects of chemical mixtures," Environmental Health Perspectives, vol. 110, no. 1, pp. 25-42, 2002.

[34] C. V. Rider, J. R. Furr, V. S. Wilson, and L. E. Gray Jr., "Cumulative effects of in utero administration of mixtures of reproductive toxicants that disrupt common target tissues via diverse mechanisms of toxicity," International Journal of Andrology, vol. 33, no. 2, pp. 443-462, 2010.

[35] A. Valavanidis, T. Vlachogianni, and K. Fiotakis, "Tobacco smoke: involvement of reactive oxygen species and stable free radicals in mechanisms of oxidative damage, carcinogenesis and synergistic effects with other respirable particles," International Journal of Environmental Research and Public Health, vol. 6, no. 2, pp. 445-462, 2009.

[36] P. L. de Fur, G. W. Evans, E. A. C. Hubal, A. D. Kyle, R. A. Morello-Frosch, and D. R. Williams, "Vulnerability as a function of individual and group resources in cumulative risk assessment," Environmental Health Perspectives, vol. 115, no. 5, pp. 817-824, 2007.

[37] R. Morello-Frosch and E. D. Shenassa, "The environmental "Riskscape" and social inequality: implications for explaining maternal and child health disparities," Environmental Health Perspectives, vol. 114, no. 8, pp. 1150-1153, 2006.

[38] J. G. Su, R. Morello-Frosch, B. M. Jesdale, A. D. Kyle, B. Shamasunder, and M. Jerrett, "An index for assessing demographic inequalities in cumulative environmental hazards with application to Los Angeles, California," Environmental Science and Technology, vol. 43, no. 20, pp. 7626-7634, 2009.

[39] G. C. Gee and D. C. Payne-Sturges, "Environmental health disparities: a framework integrating psychosocial and environmental concepts," Environmental Health Perspectives, vol. 112, no. 17, pp. 1645-1653, 2004.

[40] J. Molitor, J. G. Su, N.-T. Molitor et al., "Identifying vulnerable populations through an examination of the association between multipollutant profiles and poverty," Environmental Science \& Technology, vol. 45, no. 18, pp. 7754-7760, 2011.

[41] National Environmental Justice Advisory Council, Nationally Consistent Environmental Justice Screening Approaches, National Environmental Justice Advisory Council, Washington, DC, USA, 2010.

[42] S. H. Linder and K. Sexton, "Conceptual models for cumulative risk assessment," The American Journal of Public Health, vol. 101, no. 1, pp. S74-S81, 2011.

[43] K. Sexton and S. H. Linder, "Cumulative risk assessment for combined health effects from chemical and nonchemical stressors," American Journal of Public Health, vol. 101, supplement 1, pp. S81-S88, 2011.

[44] S. A. Robertson, "Immune regulation of conception and embryo implantation-all about quality control?" Journal of Reproductive Immunology, vol. 85, no. 1, pp. 51-57, 2010.

[45] S. Lager and T. L. Powell, "Regulation of nutrient transport across the placenta," Journal of Pregnancy, vol. 2012, Article ID 179827, 14 pages, 2012.

[46] M. F. McAleer and R. S. Tuan, "Cytotoxicant-induced trophoblast dysfunction and abnormal pregnancy outcomes: role of zinc and metallothionein," Birth Defects Research Part C: Embryo Today: Reviews, vol. 72, no. 4, pp. 361-370, 2004.

[47] M. Weinstock, "The potential influence of maternal stress hormones on development and mental health of the offspring," Brain, Behavior, and Immunity, vol. 19, no. 4, pp. 296-308, 2005.

[48] B. G. Janssen, E. Munters, N. Pieters et al., "Placental mitochondrial DNA content and particulate air pollution during in Utero life," Environmental Health Perspectives, vol. 120, no. 9, pp. 13461352, 2012.

[49] S. Stasenko, E. M. Bradford, M. Piasek et al., "Metals in human placenta: focus on the effects of cadmium on steroid hormones and leptin," Journal of Applied Toxicology, vol. 30, no. 3, pp. 242253, 2010. 
[50] W. A. Jedrychowski, F. P. Perera, D. Tang et al., “The relationship between prenatal exposure to airborne polycyclic aromatic hydrocarbons (PAHs) and PAH-DNA adducts in cord blood," Journal of Exposure Science and Environmental Epidemiology, vol. 23, no. 4, pp. 371-377, 2013.

[51] S. Sankaran and P. M. Kyle, "Aetiology and Pathogenesis of IUGR," Best Practice and Research: Clinical Obstetrics and Gynaecology, vol. 23, no. 6, pp. 765-777, 2009.

[52] P. D. Gluckman, M. A. Hanson, and C. Pinal, "The developmental origins of adult disease," Maternal and Child Nutrition, vol. 1, no. 3, pp. 130-141, 2005.

[53] J. M. Swanson, S. Entringer, C. Buss, and P. D. Wadhwa, "Developmental origins of health and disease: environmental exposures," Seminars in Reproductive Medicine, vol. 27, no. 5, pp. 391-402, 2009.

[54] M. S. Kramer, L. Goulet, J. Lydon et al., "Socio-economic disparities in preterm birth: causal pathways and mechanisms," Paediatric and Perinatal Epidemiology, vol. 15, supplement 2, pp. 104-123, 2001.

[55] S. Kannan, D. P. Misra, J. T. Dvonch, and A. Krishnakumar, "Exposures to airbone particulate matter and adverse perinatal outcomes: a biologically plausible mechanistic framework for exploring potential effect modification by nutrition," Environmental Health Perspectives, vol. 114, no. 11, pp. 1636-1642, 2006.

[56] A. M. Carter and R. Pijnenborg, "Evolution of invasive placentation with special reference to non-human primates," Best Practice \& Research: Clinical Obstetrics \& Gynaecology, vol. 25, no. 3, pp. 249-257, 2011.

[57] R. D. Martin, “The evolution of human reproduction: a primatological perspective," The American Journal of Physical Anthropology, vol. 45, pp. 59-84, 2007.

[58] I. Capellini, C. Venditti, and R. A. Barton, "Placentation and maternal investment in mammals," American Naturalist, vol. 177, no. 1, pp. 86-98, 2011.

[59] T. M. Chucri, J. M. Monteiro, A. R. Lima, M. L. B. Salvadori, J. R. K. Junior, and M. A. Miglino, "A review of immune transfer by the placenta," Journal of Reproductive Immunology, vol. 87, no. 1-2, pp. 14-20, 2010.

[60] I. Brosens, R. Pijnenborg, L. Vercruysse, and R. Romero, "The "great Obstetrical Syndromes" are associated with disorders of deep placentation," American Journal of Obstetrics \& Gynecology, vol. 204, no. 3, pp. 193-201, 2011.

[61] R. Romero, J. P. Kusanovic, T. Chaiworapongsa, and S. S. Hassan, "Placental bed disorders in preterm labor, preterm PROM, spontaneous abortion and abruptio placentae," Best Practice and Research: Clinical Obstetrics and Gynaecology, vol. 25, no. 3, pp. 313-327, 2011.

[62] Y. Khong and I. Brosens, "Defective deep placentation," Best Practice and Research: Clinical Obstetrics and Gynaecology, vol. 25, no. 3, pp. 301-311, 2011.

[63] P. H. Andraweera, G. A. Dekker, and C. T. Roberts, "The vascular endothelial growth factor family in adverse pregnancy outcomes," Human Reproduction Update, vol. 18, no. 4, Article ID dms011, pp. 436-457, 2012.

[64] D. J. P. Barker, "The origins of the developmental origins theory," Journal of Internal Medicine, vol. 261, no. 5, pp. 412-417, 2007.

[65] I. C. McMillen and J. S. Robinson, "Developmental origins of the metabolic syndrome: prediction, plasticity, and programming," Physiological Reviews, vol. 85, no. 2, pp. 571-633, 2005.
[66] J. J. Heindel, "Role of exposure to environmental chemicals in the developmental basis of reproductive disease and dysfunction," Seminars in Reproductive Medicine, vol. 24, no. 3, pp. 168177, 2006.

[67] R. Pijnenborg, L. Vercruysse, and I. Brosens, "Deep placentation," Best Practice \& Research: Clinical Obstetrics \& Gynaecology, vol. 25, no. 3, pp. 273-285, 2011.

[68] E. Jauniaux, L. Poston, and G. J. Burton, "Placental-related diseases of pregnancy: involvement of oxidative stress and implications in human evolution," Human Reproduction Update, vol. 12, no. 6, pp. 747-755, 2006.

[69] B. Sibai, G. Dekker, and M. Kupferminc, "Pre-eclampsia," The Lancet, vol. 365, no. 9461, pp. 785-799, 2005.

[70] G. J. Burton and E. Jauniaux, "Oxidative stress," Best Practice \& Research Clinical Obstetrics \& Gynaecology, vol. 25, pp. 287-299, 2011.

[71] B. J. Wlodarczyk, A. M. Palacios, C. J. Chapa, H. Zhu, T. M. George, and R. H. Finnell, "Genetic basis of susceptibility to teratogen induced birth defects," American Journal of Medical Genetics, Part C: Seminars in Medical Genetics, vol. 157, no. 3, pp. 215-226, 2011.

[72] D. A. Rappolee, A. O. Awonuga, E. E. Puscheck, S. Zhou, and Y. Xie, "Benzopyrene and experimental stressors cause compensatory differentiation in placental trophoblast stem cells," Systems Biology in Reproductive Medicine, vol. 56, no. 2, pp. 168-183, 2010.

[73] F. Perera and J. Herbstman, "Prenatal environmental exposures, epigenetics, and disease," Reproductive Toxicology, vol. 31, no. 3, pp. 363-373, 2011.

[74] J. Lewtas, "Air pollution combustion emissions: characterization of causative agents and mechanisms associated with cancer, reproductive, and cardiovascular effects," Mutation Research: Reviews in Mutation Research, vol. 636, no. 1-3, pp. 95-133, 2007.

[75] L. Stejskalova and P. Pavek, "The function of cytochrome P450 $1 \mathrm{Al}$ enzyme (CYP1A1) and aryl hydrocarbon receptor (AhR) in the placenta," Current Pharmaceutical Biotechnology, vol. 12, no. 5, pp. 715-730, 2011.

[76] T. M. C. M. de Kok, H. A. L. Driece, J. G. F. Hogervorst, and J. J. Briedé, "Toxicological assessment of ambient and trafficrelated particulate matter: a review of recent studies," Mutation Research: Reviews in Mutation Research, vol. 613, no. 2-3, pp. 103-122, 2006.

[77] L. Risom, P. Møller, and S. Loft, "Oxidative stress-induced DNA damage by particulate air pollution," Mutation Research, vol. 592, no. 1-2, pp. 119-137, 2005.

[78] A. Valavanidis, K. Fiotakis, and T. Vlachogianni, "Airborne particulate matter and human health: toxicological assessment and importance of size and composition of particles for oxidative damage and carcinogenic mechanisms," Journal of Environmental Science and Health, Part C: Environmental Carcinogenesis and Ecotoxicology Reviews, vol. 26, no. 4, pp. 339-362, 2008.

[79] N. Li, C. Sioutas, A. Cho et al., "Ultrafine particulate pollutants induce oxidative stress and mitochondrial damage," Environmental Health Perspectives, vol. 111, no. 4, pp. 455-460, 2003.

[80] M. Brauer, C. Lencar, L. Tamburic, M. Koehoorn, P. Demers, and C. Karr, "A cohort study of traffic-related air pollution impacts on birth outcomes," Environmental Health Perspectives, vol. 116, no. 5, pp. 680-686, 2008.

[81] S. Liu, D. Krewski, Y. Shi, Y. Chen, and R. T. Burnett, "Association between gaseous ambient air pollutants and adverse 
pregnancy outcomes in Vancouver, Canada," Environmental Health Perspectives, vol. 111, no. 14, pp. 1773-1778, 2003.

[82] R. Resnik, "Intrauterine growth restriction," Obstetrics and Gynecology, vol. 99, no. 3, pp. 490-496, 2002.

[83] R. E. Behrman and A. S. Butler, Eds., Preterm Birth: Causes, Consequences, and Prevention, National Acadamies Press, Washington, DC, USA, 2007.

[84] S. Petrou, "Economic consequences of preterm birth and low birthweight," BJOG, vol. 110, supplement 20, pp. 117-123, 2003.

[85] S. Saigal and L. W. Doyle, "An overview of mortality and sequelae of preterm birth from infancy to adulthood," The Lancet, vol. 371, no. 9608, pp. 261-269, 2008.

[86] R. L. Williams, R. K. Creasy, G. C. Cunningham, W. E. Hawes, F. D. Norris, and M. Tashiro, "Fetal growth and perinatal viability in California," Obstetrics and Gynecology, vol. 59, no. 5, pp. 624632, 1982.

[87] D. R. Boyd and S. J. Genuis, "The environmental burden of disease in Canada: respiratory disease, cardiovascular disease, cancer, and congenital affliction," Environmental Research, vol. 106, no. 2, pp. 240-249, 2008.

[88] Priority Substances List Assessment Report for Respirable Particulate Matter Less Than 10 microns, Environment Canada, Health Canada, Ottawa, Canada, 2000.

[89] US Environmental Protection Agency, Integrated Science Assessment for Particulate Matter (Final Report), US Environmental Protection Agency, Washington, DC, USA, 2009.

[90] D. W. Dockery and C. A. Pope, "Acute respiratory effects of particulate air pollution," Annual Review of Public Health, vol. 15, pp. 107-132, 1994.

[91] R. M. Harrison, A. M. Jones, and R. G. Lawrence, "Major component composition of PM10 and PM2.5 from roadside and urban background sites," Atmospheric Environment, vol. 38, no. 27, pp. 4531-4538, 2004.

[92] W. H. Schroeder, M. Dobson, D. M. Kane, and N. D. Johnson, "Toxic trace elements associated with airborne particulate matter: a review," Journal of the Air Pollution Control Association, vol. 37, no. 11, pp. 1267-1285, 1987.

[93] H. Boogaard, G. P. A. Kos, E. P. Weijers et al., "Contrast in air pollution components between major streets and background locations: Particulate matter mass, black carbon, elemental composition, nitrogen oxide and ultrafine particle number," Atmospheric Environment, vol. 45, no. 3, pp. 650-658, 2011.

[94] M. L. Bell and K. Belanger, "Review of research on residential mobility during pregnancy: consequences for assessment of prenatal environmental exposures," Journal of Exposure Science and Environmental Epidemiology, vol. 22, no. 5, pp. 429-438, 2012.

[95] M. L. Bell and K. Ebisu, "Environmental inequality in exposures to airborne particulate matter components in the United States," Environmental Health Perspectives, vol. 120, no. 12, pp. 16991704, 2012.

[96] H. Boogaard, N. A. H. Janssen, P. H. Fischer et al., "Contrasts in oxidative potential and other particulate matter characteristics collected near major streets and background locations," Environmental Health Perspectives, vol. 120, no. 2, pp. 185-191, 2012.

[97] K. Donaldson, V. Stone, A. Seaton, and W. MacNee, "Ambient particle inhalation and the cardiovascular system: potential mechanisms," Environmental Health Perspectives, vol. 109, supplement, pp. 523-527, 2001.

[98] HEI Review Panel on Ultrafine Particles, Understanding the Health Effects of Ambient Ultrafine Particles, HEI Perspectives, Boston, Mass, USA, 2013.
[99] A. J. Ghio, J. R. Sobus, J. D. Pleil, and M. C. Madden, “Controlled human exposures to diesel exhaust," Swiss Medical Weekly, vol. 142, Article ID w13597, 2012.

[100] C. S. Weldy, Y. Liu, H. D. Liggitt, and M. T. Chin, "In utero exposure to diesel exhaust air pollution promotes adverse intrauterine conditions, resulting in weight gain, altered blood pressure, and increased susceptibility to heart failure in adult mice," PLoS ONE, vol. 9, Article ID e88582, 2014.

[101] K. Takeda, N. Tsukue, and S. Yoshida, "Endocrine-disrupting activity of chemicals in diesel exhaust and diesel exhaust particles," Environmental Sciences, vol. 11, no. 1, pp. 33-45, 2004.

[102] Agency for Toxic Substances and Disease Registry (ATSDR), Toxicological Profile for Polycyclic Aromatic Hydrocarbons, Agency for Toxic Substances and Disease Registry (ATSDR), Atlanta, Ga, USA, 1995.

[103] B. C. Gladen, T. D. Zadorozhnaja, N. Chislovska, D. O. Hryhorczuk, M. C. Kennicutt II, and R. E. Little, "Polycyclic aromatic hydrocarbons in placenta," Human \& Experimental Toxicology, vol. 19, no. 11, pp. 597-603, 2000.

[104] Environmental Protection Agency, Supplementary Guidance for Conducting Health Risk Assessment of Chemical Mixtures, U.S. Environmental Protection Agency, Washington, DC, USA, 2000.

[105] H. Líbalová, S. Krčková, K. Uhlířová et al., "Genotoxicity but not the AhR-mediated activity of PAHs is inhibited by other components of complex mixtures of ambient air pollutants," Toxicology Letters, vol. 225, no. 3, pp. 350-357, 2014.

[106] Environment Canada and Health Canada, Priority Substances List Assessment Report for Polycyclic Aromatic Hydrocarbons, Environment Canada, Health Canada, Ottawa, Canada, 1994.

[107] X. Y. Li, P. S. Gilmour, K. Donaldson, and W. MacNee, "Free radical activity and pro-inflammatory effect of particulate air pollution (PM10) in vivo and in vitro," Thorax, vol. 51, no. 12, pp. 1216-1222, 1996.

[108] M. R. Miller, C. A. Shaw, and J. P. Langrish, "From particles to patients: oxidative stress and the cardiovascular effects of air pollution," Future Cardiology, vol. 8, no. 4, pp. 577-602, 2012.

[109] B. Z. Simkhovich, M. T. Kleinman, and R. A. Kloner, "Air pollution and cardiovascular injury: epidemiology, toxicology, and mechanisms," Journal of the American College of Cardiology, vol. 52, no. 9, pp. 719-726, 2008.

[110] R. Morello-Frosch, M. Zuk, M. Jerrett, B. Shamasunder, and A. D. Kyle, "Understanding the cumulative impacts of inequalities in environmental health: implications for policy," Health Affairs, vol. 30, no. 5, pp. 879-887, 2011.

[111] D. Krewski, M. Jerrett, R. T. Burnett et al., "Extended followup and spatial analysis of the American Cancer Society study linking particulate air pollution and mortality," Research Report (Health Effects Institute), vol. 140, pp. 5-114, 2009.

[112] P. Tanuseputro, D. G. Manuel, M. Leung, K. Nguyen, and H. Johansen, "Risk factors for cardiovascular disease in Canada," Canadian Journal of Cardiology, vol. 19, no. 11, pp. 1249-1259, 2003.

[113] D. S. Lee, M. Chiu, D. G. Manuel et al., "Trends in risk factors for cardiovascular disease in Canada: temporal, sociodemographic and geographic factors," $C M A J$, vol. 181, no. 3-4, pp. E55-E66, 2009.

[114] S. Kannan, J. T. Dvonch, A. J. Schulz et al., "Exposure to fine particulate matter and acute effects on blood pressure: Effect modification by measures of obesity and location," Journal of Epidemiology and Community Health, vol. 64, no. 1, pp. 68-74, 2010. 
[115] C. E. Powe, R. J. Levine, and S. A. Karumanchi, "Preeclampsia, a disease of the maternal endothelium: the role of antiangiogenic factors and implications for later cardiovascular disease," Circulation, vol. 123, no. 24, pp. 2856-2869, 2011.

[116] L. Poston, "Endothelial dysfunction in pre-eclampsia," Pharmacological Reports, vol. 58, pp. 69-74, 2006.

[117] S. Louey and K. L. Thornburg, "The prenatal environment and later cardiovascular disease," Early Human Development, vol. 81, no. 9, pp. 745-751, 2005.

[118] L. Poston, N. Igosheva, H. D. Mistry et al., "Role of oxidative stress and antioxidant supplementation in pregnancy disorders," The American Journal of Clinical Nutrition, vol. 94, no. 6, pp. 1980S-1985S, 2011.

[119] A. A. Mangoni and S. H. D. Jackson, "Homocysteine and cardiovascular disease: current evidence and future prospects," The American Journal of Medicine, vol. 112, no. 7, pp. 556-565, 2002.

[120] M. S. Kramer, S. R. Kahn, R. Rozen et al., "Vasculopathic and thrombophilic risk factors for spontaneous preterm birth," International Journal of Epidemiology, vol. 38, no. 3, pp. 715-723, 2009.

[121] G. Assmann and J.-R. Nofer, "Atheroprotective effects of highdensity lipoproteins," Annual Review of Medicine, vol. 54, pp. 321-341, 2003.

[122] K. A. Bocskay, D. Tang, M. A. Orjuela, X. Liu, D. P. Warburton, and F. P. Perera, "Chromosomal aberrations in cord blood are associated with prenatal exposure to carcinogenic polycyclic aromatic hydrocarbons," Cancer Epidemiology Biomarkerse Prevention, vol. 14, no. 2, pp. 506-511, 2005.

[123] F. Perera, D. Tang, R. Whyatt, S. A. Lederman, and W. Jedrychowski, "DNA damage from polycyclic aromatic hydrocarbons measured by benzo[a]pyrene-DNA adducts in mothers and newborns from Northern Manhattan, the World Trade Center Area, Poland, and China," Cancer Epidemiology Biomarkers and Prevention, vol. 14, no. 3, pp. 709-714, 2005.

[124] P. J. Lupo, P. H. Langlois, J. Reefhuis et al., "Maternal occupational exposure to polycyclic aromatic hydrocarbons: effects on gastroschisis among offspring in the national birth defects prevention study," Environmental Health Perspectives, vol. 120, no. 6, pp. 910-915, 2012.

[125] D. R. Mattison, "Environmental exposures and development," Current Opinion in Pediatrics, vol. 22, no. 2, pp. 208-218, 2010.

[126] R. L. Brent, "Environmental causes of human congenital malformations: the pediatrician's role in dealing with these complex clinical problems caused by a multiplicity of environmental and genetic factors," Pediatrics, vol. 113, no. 4, pp. 957-968, 2004.

[127] A. Hackshaw, C. Rodeck, and S. Boniface, "Maternal smoking in pregnancy and birth defects: A systematic review based on 173687 malformed cases and 11.7 million controls," Human Reproduction Update, vol. 17, no. 5, pp. 589-604, 2011.

[128] I. Cetin, C. Berti, and S. Calabrese, "Role of micronutrients in the periconceptional period," Human Reproduction Update, vol. 16, no. 1, pp. 80-95, 2009.

[129] R. Lim, G. Barker, C. A. Wall, and M. Lappas, "Dietary phytophenols curcumin, naringenin and apigenin reduce infectioninduced inflammatory and contractile pathways in human placenta, foetal membranes and myometrium," Molecular Human Reproduction, vol. 19, no. 7, pp. 451-462, 2013.

[130] M. Guxens, I. Aguilera, F. Ballester et al., "Prenatal exposure to residential air pollution and infant mental development: modulation by antioxidants and detoxification factors," Environmental Health Perspectives, vol. 120, no. 1, pp. 144-149, 2012.
[131] M. Pedersen, B. Schoket, R. W. Godschalk et al., "Bulky DNA adducts in cord blood, maternal fruit-and-vegetable consumption, and birth weight in a European mother-child study (NewGeneris)," Environmental Health Perspectives, vol. 121, no. 10, pp. 1200-1206, 2013.

[132] T. Zdravkovic, O. Genbacev, M. T. McMaster, and S. J. Fisher, "The adverse effects of maternal smoking on the human placenta: a review," Placenta, vol. 26, pp. S81-S86, 2005.

[133] C. A. Northrop-Clewes and D. I. Thurnham, "Monitoring micronutrients in cigarette smokers," Clinica Chimica Acta, vol. 377, no. 1-2, pp. 14-38, 2007.

[134] E. Jauniaux and G. J. Burton, "Morphological and biological effects of maternal exposure to tobacco smoke on the fetoplacental unit," Early Human Development, vol. 83, no. 11, pp. 699-706, 2007.

[135] H. C. Sorkun, F. Bir, M. Akbulut et al., "The effects of air pollution and smoking on placental cadmium, zinc concentration and metallothionein expression," Toxicology, vol. 238, no. 1, pp. 15-22, 2007.

[136] B. Marciniak, J. Patro-Malysza, E. Poniedziałek-Czajkowska, Z. Kimber-Trojnar, B. Leszczyńska-Gorzelak, and J. Oleszczuk, "Glucocorticoids in pregnancy," Current Pharmaceutical Biotechnology, vol. 12, no. 5, pp. 750-757, 2011.

[137] J. E. Clougherty and L. D. Kubzansky, "A framework for examining social stress and susceptibility to air pollution in respiratory health," Environmental Health Perspectives, vol. 117, no. 9, pp. 1351-1358, 2009.

[138] J. Mairesse, J. Lesage, C. Breton et al., "Maternal stress alters endocrine function of the feto-placental unit in rats," The American Journal of Physiology -Endocrinology and Metabolism, vol. 292, no. 6, pp. E1526-E1533, 2007.

[139] F. M. Haste, O. G. Brooke, H. R. Anderson, J. M. Bland, and J. L. Peacock, "Social determinants of nutrient intake in smokers and non-smokers during pregnancy," Journal of Epidemiology and Community Health, vol. 44, no. 3, pp. 205-209, 1990.

[140] F. M. Haste, O. G. Brooke, H. R. Anderson, and J. M. Bland, "The effect of nutritional intake on outcome of pregnancy in smokers and non-smokers," British Journal of Nutrition, vol. 65, no. 3, pp. 347-354, 1991.

[141] S. L. Rifas-Shiman, J. W. Rich-Edwards, K. P. Kleinman, E. Oken, and M. W. Gillman, "Dietary quality during pregnancy varies by maternal characteristics in Project Viva: a US cohort," Journal of the American Dietetic Association, vol. 109, no. 6, pp. 1004-1011, 2009.

[142] P. N. Baker, S. J. Wheeler, T. A. Sanders et al., "A prospective study of micronutrient status in adolescent pregnancy," The American Journal of Clinical Nutrition, vol. 89, no. 4, pp. 11141124, 2009.

[143] B. Hennig, L. Ormsbee, C. J. McClain et al., "Nutrition can modulate the toxicity of environmental pollutants: Implications in risk assessment and human health," Environmental Health Perspectives, vol. 120, no. 6, pp. 771-774, 2012.

[144] G. Salmasi, R. Grady, J. Jones, and S. D. McDonald, "Environmental tobacco smoke exposure and perinatal outcomes: a systematic review and meta-analyses," Acta Obstetricia et Gynecologica Scandinavica, vol. 89, no. 4, pp. 423-441, 2010.

[145] J. Dejmek, I. Solansky, K. Podrazilová, and R. J. Šrám, “The exposure of nonsmoking and smoking mothers to environmental tobacco smoke during different gestational phases and fetal growth," Environmental Health Perspectives, vol. 110, no. 6, pp. 601-606, 2002. 
[146] A. Castles, E. K. Adams, C. L. Melvin, C. Kelsch, and M. L. Boulton, "Effects of smoking during pregnancy: five metaanalyses," American Journal of Preventive Medicine, vol. 16, no. 3, pp. 208-215, 1999.

[147] A. C. Erickson and L. T. Arbour, "Heavy smoking during pregnancy as a marker for other risk factors of adverse birth outcomes: a population-based study in British Columbia, Canada," BMC Public Health, vol. 12, no. 1, article 102, 2012.

[148] M. Mohsin and A. E. Bauman, "Socio-demographic factors associated with smoking and smoking cessation among 426,344 pregnant women in New South Wales, Australia," BMC Public Health, vol. 5, article 138, 2005.

[149] S. Schneider, H. Maul, N. Freerksen, and M. Pötschke-Langer, "Who smokes during pregnancy? An analysis of the German Perinatal Quality Survey 2005," Public Health, vol. 122, no. 11, pp. 1210-1216, 2008.

[150] S. Krishnan, Y. C. Cozier, L. Rosenberg, and J. R. Palmer, "Socioeconomic status and incidence of type 2 diabetes: results from the black women's health study," American Journal of Epidemiology, vol. 171, no. 5, pp. 564-570, 2010.

[151] S. D. Dubowsky, H. Suh, J. Schwartz, B. A. Coull, and D. R. Gold, "Diabetes, obesity, and hypertension may enhance associations between air pollution and markers of systemic inflammation," Environmental Health Perspectives, vol. 114, no. 7, pp. 992-998, 2006.

[152] J. C. Chen, J. M. Cavallari, P. H. Stone, and D. C. Christiani, "Obesity is a modifier of automatic cardiac responses to fine metal particulates," Environmental Health Perspectives, vol. 115, no. 7, pp. 1002-1006, 2007.

[153] E. Malmqvist, K. Jakobsson, H. Tinnerberg, A. RignellHydbom, and L. Rylander, "Gestational diabetes and preeclampsia in association with air pollution at levels below current air quality guidelines," Environmental Health Perspectives, vol. 121, no. 4, pp. 488-493, 2013.

[154] G. Pereira, F. Haggar, A. W. Shand, C. Bower, A. Cook, and N. Nassar, "Association between pre-eclampsia and locally derived traffic-related air pollution: a retrospective cohort study," Journal of Epidemiology and Community Health, vol. 67, no. 2, pp. 147-152, 2013.

[155] P. Dadvand, F. Figueras, X. Basagaña et al., "Ambient air pollution and preeclampsia: a spatiotemporal analysis," Environmental Health Perspectives, vol. 121, no. 11-12, pp. 1365-1371, 2013.

[156] J. Wu, C. Ren, R. J. Delfino, J. Chung, M. Wilhelm, and B. Ritz, "Association between local traffic-generated air pollution and preeclampsia and preterm delivery in the South Coast Air Basin of california," Environmental Health Perspectives, vol. 117, no. 11, pp. 1773-1779, 2009.

[157] T. L. Gruenewald, A. S. Karlamangla, P. Hu et al., "History of socioeconomic disadvantage and allostatic load in later life," Social Science and Medicine, vol. 74, no. 1, pp. 75-83, 2012.

[158] T. E. Seeman, B. S. McEwen, J. W. Rowe, and B. H. Singer, "Allostatic load as a marker of cumulative biological risk: MacArthur studies of successful aging," Proceedings of the National Academy of Sciences of the United States of America, vol. 98, no. 8, pp. 4770-4775, 2001.

[159] C. E. Bird, T. Seeman, J. J. Escarce et al., "Neighbourhood socioeconomic status and biological "wear and tear" in a nationally representative sample of US adults," Journal of Epidemiology and Community Health, vol. 64, no. 10, pp. 860-865, 2010.
[160] A. V. D. Roux, "Investigating neighborhood and area effects on health," American Journal of Public Health, vol. 91, no. 11, pp. 1783-1789, 2001.

[161] N. Auger, J. Giraud, and M. Daniel, “The joint influence of area income, income inequality, and immigrant density on adverse birth outcomes: a population-based study," BMC Public Health, vol. 9, article 237, 2009.

[162] M. Tegethoff, N. Greene, J. Olsen, E. Schaffner, and G. Meinlschmidt, "Stress during pregnancy and offspring pediatric disease: a national cohort study," Environmental Health Perspectives, vol. 119, no. 11, pp. 1647-1652, 2011.

[163] B. S. Mcewen and P. J. Gianaros, "Central role of the brain in stress and adaptation: links to socioeconomic status, health, and disease," Annals of the New York Academy of Sciences, vol. 1186, pp. 190-222, 2010.

[164] B. S. McEwen, "Brain on stress: how the social environment gets under the skin," Proceedings of the National Academy of Sciences of the United States of America, vol. 109, no. 2, pp. 17180-17185, 2012.

[165] I. N. Karatsoreos and B. S. McEwen, "Psychobiological allostasis: Resistance, resilience and vulnerability," Trends in Cognitive Sciences, vol. 15, no. 12, pp. 576-584, 2011.

[166] R. M. Sapolsky, L. M. Romero, and A. U. Munck, "How do glucocorticoids influence stress responses? Integrating permissive, suppressive, stimulatory, and preparative actions," Endocrine Reviews, vol. 21, no. 1, pp. 55-89, 2000.

[167] K. J. Davies, "Oxidative stress: the paradox of aerobic life," Biochemical Society Symposium, vol. 61, pp. 1-31, 1995.

[168] K. H. Al-Gubory, P. A. Fowler, and C. Garrel, "The roles of cellular reactive oxygen species, oxidative stress and antioxidants in pregnancy outcomes," The International Journal of Biochemistry \& Cell Biology, vol. 42, no. 10, pp. 1634-1650, 2010.

[169] K. J. Davies, "Oxidative stress, antioxidant defenses, and damage removal, repair, and replacement systems," IUBMB Life, vol. 50, no. 4-5, pp. 279-289, 2000.

[170] D. A. Ferenbach, D. C. Kluth, and J. Hughes, "Hemeoxygenase1 and renal ischaemia-reperfusion injury," NephronExperimental Nephrology, vol. 115, no. 3, pp. e33-e37, 2010.

[171] K. Levytska, J. Kingdom, D. Baczyk, and S. Drewlo, "Heme oxygenase-1 in placental development and pathology," Placenta, vol. 34, no. 4, pp. 291-298, 2013.

[172] H. Zhao, R. J. Wong, F. S. Kalish, N. R. Nayak, and D. K. Stevenson, "Effect of heme oxygenase-1 deficiency on placental development," Placenta, vol. 30, no. 10, pp. 861-868, 2009.

[173] A. Munoz-Suano, A. B. Hamilton, and A. G. Betz, "Gimme shelter: the immune system during pregnancy," Immunological Reviews, vol. 241, no. 1, pp. 20-38, 2011.

[174] J. R. Prins, N. Gomez-Lopez, and S. A. Robertson, "Interleukin6 in pregnancy and gestational disorders," Journal of Reproductive Immunology, vol. 95, no. 1-2, pp. 1-14, 2012.

[175] I. Gerhard, S. Waibel, V. Daniel, and B. Runnebaum, "Impact of heavy metals on hormonal and immunological factors in women with repeated miscarriages," Human Reproduction Update, vol. 4, no. 3, pp. 301-309, 1998.

[176] P.-C. Lee, E. O. Talbott, J. M. Roberts, J. M. Catov, R. K. Sharma, and B. Ritz, "Particulate air pollution exposure and C-reactive protein during early pregnancy," Epidemiology, vol. 22, no. 4, pp. 524-531, 2011.

[177] F. Vadillo-Ortega, A. Osornio-Vargas, M. A. Buxton et al., "Air pollution, inflammation and preterm birth: a potential mechanistic link," Medical Hypotheses, vol. 82, no. 2, pp. 219224, 2014. 
[178] B. S. McEwen and P. Tucker, "Critical biological pathways for chronic psychosocial stress and research opportunities to advance the consideration of stress in chemical risk assessment," American Journal of Public Health, vol. 101, supplement 1, pp. S131-S139, 2011.

[179] C. W. G. Redman, D. S. Tannetta, R. A. Dragovic et al., "Review: does size matter? Placental debris and the pathophysiology of pre-eclampsia," Placenta, vol. 33, pp. S48-S54, 2012.

[180] J. D. Pleil and L. S. Sheldon, "Adapting concepts from systems biology to develop systems exposure event networks for exposure science research," Biomarkers, vol. 16, no. 2, pp. 99-105, 2011.

[181] N. G. Than, R. Romero, A. L. Tarca et al., "Mitochondrial manganese superoxide dismutase mRNA expression in human chorioamniotic membranes and its association with labor, inflammation, and infection," Journal of Maternal-Fetal and Neonatal Medicine, vol. 22, no. 11, pp. 1000-1013, 2009.

[182] J. M. Bowen, L. Chamley, J. A. Keelan, and M. D. Mitchell, "Cytokines of the placenta and extra-placental membranes: Roles and regulation during human pregnancy and parturition," Placenta, vol. 23, no. 4, pp. 257-273, 2002.

[183] J. M. Bowen, L. Chamley, M. D. Mitchell, and J. A. Keelan, "Cytokines of the placenta and extra-placental membranes: biosynthesis, secretion and roles in establishment of pregnancy in women," Placenta, vol. 23, no. 4, pp. 239-256, 2002.

[184] N. G. Than, R. Romero, C. J. Kim, M. R. McGowen, Z. Papp, and D. E. Wildman, "Galectins: Guardians of eutherian pregnancy at the maternal-fetal interface," Trends in Endocrinology and Metabolism, vol. 23, no. 1, pp. 23-31, 2012.

[185] J. Thompson and J. Bannigan, "Cadmium: toxic effects on the reproductive system and the embryo," Reproductive Toxicology, vol. 25, no. 3, pp. 304-315, 2008.

[186] M. C. Henson and P. J. Chedrese, "Endocrine disruption by cadmium, a common environmental toxicant with paradoxical effects on reproduction," Experimental Biology and Medicine, vol. 229, no. 5, pp. 383-392, 2004.

[187] A. J. Dunn, "The HPA axis and the immune system: a perspective," in NeuroImmune Biology, A. del Rey, G. P. Chrousos, and H. O. Besedovsky, Eds., vol. 7, pp. 3-15, NeuroImmune Biology, Elsevier, 2007.

[188] S. A. Venners, X. Wang, C. Chen et al., "Paternal smoking and pregnancy loss: a prospective study using a biomarker of pregnancy," The American Journal of Epidemiology, vol. 159, no. 10, pp. 993-1001, 2004.

[189] A. G. Ronnenberg, S. A. Venners, X. Xu et al., "Preconception B-vitamin and homocysteine status, conception, and early pregnancy loss," American Journal of Epidemiology, vol. 166, no. 3, pp. 304-312, 2007.

[190] R. Slama, S. Bottagisi, I. Solansky, J. Lepeule, L. GiorgisAllemand, and R. Sram, "Short-term impact of atmospheric pollution on fecundability," Epidemiology, vol. 24, no. 6, pp. 871879, 2013.

[191] M. J. Nieuwenhuijsen, X. Basagaña, P. Dadvand et al., "Air pollution and human fertility rates," Environment International, vol. 70, pp. 9-14, 2014.

[192] E. Jauniaux, A. L. Watson, J. Hempstock, Y.-P. Bao, J. N. Skepper, and G. J. Burton, "Onset of maternal arterial blood flow and placental oxidative stress: a possible factor in human early pregnancy failure," The American Journal of Pathology, vol. 157, no. 6 , pp. 2111-2122, 2000.

[193] A. E. Wallace, R. Fraser, and J. E. Cartwright, "Extravillous trophoblast and decidual natural killer cells: a remodelling partnership," Human Reproduction Update, vol. 18, no. 4, Article ID dms015, pp. 458-471, 2012.

[194] C. W. G. Redman and I. L. Sargent, "Placental stress and preeclampsia: a revised view," Placenta, vol. 30, pp. 38-42, 2009.

[195] R. Gagnon, "Placental insufficiency and its consequences," European Journal of Obstetrics Gynecology and Reproductive Biology, vol. 110, pp. S99-S107, 2003.

[196] F.-J. Lin., J. W. Fitzpatrick, C. A. Iannotti, D. S. Martin, B. D. Mariani, and R. S. Tuan, "Effects of cadmium on trophoblast calcium transport," Placenta, vol. 18, no. 4, pp. 341-356, 1997.

[197] T. K. Morgan, J. E. Tolosa, L. Mele et al., "Placental villous hypermaturation is associated with idiopathic preterm birth," Journal of Maternal-Fetal and Neonatal Medicine, vol. 26, no. 7, pp. 647-653, 2013.

[198] V. Bollati, B. Marinelli, P. Apostoli et al., "Exposure to metalrich particulate matter modifies the expression of candidate MicroRNAs in peripheral blood leukocytes," Environmental Health Perspectives, vol. 118, no. 6, pp. 763-768, 2010.

[199] R. Slama, L. Darrow, J. Parker et al., "Meeting report: atmospheric pollution and human reproduction," Environmental Health Perspectives, vol. 116, no. 6, pp. 791-798, 2008.

[200] E. H. van den Hooven, Y. de Kluizenaar, F. H. Pierik et al., "Chronic air pollution exposure during pregnancy and maternal and fetal c-reactive protein levels: the generation $\mathrm{R}$ study," Environmental Health Perspectives, vol. 120, no. 5, pp. 746-751, 2012.

[201] S. Salvi, A. Blomberg, B. Rudell et al., "Acute inflammatory responses in the airways and peripheral blood after shortterm exposure to diesel exhaust in healthy human volunteers," American Journal of Respiratory and Critical Care Medicine, vol. 159, no. 3, pp. 702-709, 1999.

[202] S.-Q. Wei, W. Fraser, and Z.-C. Luo, "Inflammatory cytokines and spontaneous preterm birth in asymptomatic women: a systematic review," Obstetrics and Gynecology, vol. 116, no. 2, pp. 393-401, 2010.

[203] K. Monostory, J.-M. Pascussi, L. Kóbori, and Z. Dvorak, "Hormonal regulation of CYP1A expression," Drug Metabolism Reviews, vol. 41, no. 4, pp. 547-572, 2009.

[204] A. C. Collier, M. D. Tingle, J. W. Paxton, M. D. Mitchell, and J. A. Keelan, "Metabolizing enzyme localization and activities in the first trimester human placenta: the effect of maternal and gestational age, smoking and alcohol consumption," Human Reproduction, vol. 17, no. 10, pp. 2564-2572, 2002.

[205] J. Vondráček, L. Umannová, and M. Machala, "Interactions of the aryl hydrocarbon receptor with inflammatory mediators: beyond CYP1A regulation," Current Drug Metabolism, vol. 12, no. 2, pp. 89-103, 2011.

[206] H. Choi, V. Rauh, R. Garfinkel, Y. Tu, and F. P. Perera, "Prenatal exposure to airborne polycyclic aromatic hydrocarbons and risk of intrauterine growth restriction," Environmental Health Perspectives, vol. 116, no. 5, pp. 658-665, 2008.

[207] H. Choi, L. Wang, X. Lin, J. D. Spengler, and F. P. Perera, "Fetal window of vulnerability to airborne polycyclic aromatic hydrocarbons on proportional intrauterine growth restriction," PLoS ONE, vol. 7, no. 4, Article ID e35464, 2012.

[208] M. P. Rayman, "The importance of selenium to human health," The Lancet, vol. 356, no. 9225, pp. 233-241, 2000.

[209] J. Chen and M. J. Berry, "Selenium and selenoproteins in the brain and brain diseases," Journal of Neurochemistry, vol. 86, no. 1, pp. 1-12, 2003. 
[210] A. S. Al-Kunani, R. Knight, S. J. Haswell, J. W. Thompson, and S. W. Lindow, "The selenium status of women with a history of recurrent miscarriage," British Journal of Obstetrics and Gynaecology, vol. 108, no. 10, pp. 1094-1097, 2001.

[211] B. A. Zachara, W. Dobrzyński, U. Trafikowska, and W. Szymański, "Blood selenium and glutathione peroxidases in miscarriage," British Journal of Obstetrics and Gynaecology, vol. 108, no. 3, pp. 244-247, 2001.

[212] J. M. Howard, S. Davies, and A. Hunnisett, "Red cell magnesium and glutathione peroxidase in infertile women-effects of oral supplementation with magnesium and selenium," Magnesium Research, vol. 7, no. 1, pp. 49-57, 1994.

[213] W. Dobrzynski, U. Trafikowska, A. Trafikowska, A. Pilecki, W. Szymanski, and B. A. Zachara, "Decreased selenium concentration in maternal and cord blood in preterm compared with term delivery," Analyst, vol. 123, no. 1, pp. 93-97, 1998.

[214] H. D. Mistry, V. Wilson, M. M. Ramsay, M. E. Symonds, and F. B. Pipkin, "Reduced selenium concentrations and glutathione peroxidase activity in preeclamptic pregnancies," Hypertension, vol. 52, no. 5, pp. 881-888, 2008.

[215] J. Vanderlelie and A. V. A. Perkins, "Selenium and preeclampsia: a global perspective," Pregnancy Hypertension, vol. 1, no. 3-4, pp. 213-224, 2011.

[216] C. Bertram, A. R. Trowern, N. Copin, A. A. Jackson, and C. B. Whorwood, "The maternal diet during pregnancy programs altered expression of the glucocorticoid receptor and type 2 $11 \beta$-hydroxysteroid dehydrogenase: potential molecular mechanisms underlying the programming of hypertension in utero," Endocrinology, vol. 142, no. 7, pp. 2841-2853, 2001.

[217] K. Yang, L. Julan, F. Rubio, A. Sharma, and H. Guan, "Cadmium reduces $11 \beta$-hydroxysteroid dehydrogenase type 2 activity and expression in human placental trophoblast cells," American Journal of Physiology: Endocrinology and Metabolism, vol. 290, no. 1, pp. E135-E142, 2006.

[218] M. Piasek, M. Blanuša, K. Kostial, and J. W. Laskey, "Placental cadmium and progesterone concentrations in cigarette smokers," Reproductive Toxicology, vol. 15, no. 6, pp. 673-681, 2001.

[219] D. Rurak, "Placental development and function," in Fetal Growth and Development, R. Harding and A. D. Bocking, Eds., Cambridge University Press, Cambridge, Mass, USA, 2001.

[220] M. S. Kramer, S. R. Kahn, R. W. Platt et al., "Antioxidant vitamins, long-chain fatty acids, and spontaneous preterm birth," Epidemiology, vol. 20, no. 5, pp. 707-713, 2009.

[221] A. Dragani, A. Falco, F. Santilli et al., "Oxidative stress and platelet activation in subjects with moderate hyperhomocysteinaemia due to MTHFR $677 \mathrm{C} \rightarrow \mathrm{T}$ polymorphism," Thrombosis and Haemostasis, vol. 108, no. 3, pp. 533-542, 2012.

[222] B. De Chiara, V. Sedda, M. Parolini et al., "Plasma total cysteine and cardiovascular risk burden: action and interaction," The Scientific World Journal, vol. 2012, Article ID 303654, 7 pages, 2012.

[223] C. E. García-Rodríguez, M. D. Mesa, J. Olza et al., "Does consumption of two portions of salmon per week enhance the antioxidant defense system in pregnant women?" Antioxidantse Redox Signaling, vol. 16, no. 12, pp. 1401-1406, 2012.

[224] A. R. Patten, P. S. Brocardo, and B. R. Christie, "Omega3 supplementation can restore glutathione levels and prevent oxidative damage caused by prenatal ethanol exposure," Journal of Nutritional Biochemistry, vol. 24, no. 5, pp. 760-769, 2013.

[225] S. Roy, A. Kale, K. Dangat, P. Sable, A. Kulkarni, and S. Joshi, "Maternal micronutrients (folic acid and vitamin $\mathrm{B}_{12}$ ) and omega 3 fatty acids: implications for neurodevelopmental risk in the rat offspring," Brain and Development, vol. 34, no. 1, pp. 64-71, 2012.

[226] A. M. Ronco, F. Garrido, and M. N. Llanos, "Smoking specifically induces metallothionein-2 isoform in human placenta at term," Toxicology, vol. 223, no. 1-2, pp. 46-53, 2006.

[227] M. Kippler, A. M. W. Hoque, R. Raqib, H. Öhrvik, E.-C. Ekström, and M. Vahter, "Accumulation of cadmium in human placenta interacts with the transport of micronutrients to the fetus," Toxicology Letters, vol. 192, no. 2, pp. 162-168, 2010.

[228] Agency for Toxic Substances and Disease Registry, Toxicological Profile for Cadmium, Agency for Toxic Substances and Disease Registry, Atlanta, Ga, USA, 2012.

[229] L. P. Nampoothiri and S. Gupta, "Biochemical effects of gestational coexposure to lead and cadmium on reproductive performance, placenta, and ovary," Journal of Biochemical and Molecular Toxicology, vol. 22, no. 5, pp. 337-344, 2008.

[230] S. M. Engel, E. Scher, S. Wallenstein et al., "Maternal active and passive smoking and hypertensive disorders of pregnancy: Risk with trimester-specific exposures," Epidemiology, vol. 24, no. 3, pp. 379-386, 2013.

[231] R. M. Reynolds, J. Labad, C. Buss, P. Ghaemmaghami, and K. Räikkönen, "Transmitting biological effects of stress in utero: implications for mother and offspring," Psychoneuroendocrinology, vol. 38, no. 9, pp. 1843-1849, 2013.

[232] R. L. Goldenberg, J. F. Culhane, J. D. Iams, and R. Romero, "Epidemiology and causes of preterm birth," The Lancet, vol. 371, no. 9606, pp. 75-84, 2008.

[233] C. A. Sandman, P. D. Wadhwa, A. Chicz-DeMet, C. DunkelSchetter, and M. Porto, "Maternal stress, HPA activity, and fetal/infant outcome," Annals of the New York Academy of Sciences, vol. 814, pp. 266-275, 1997.

[234] C. A. Sandman, L. Glynn, C. D. Schetter et al., "Elevated maternal cortisol early in pregnancy predicts third trimester levels of placental corticotropin releasing hormone $(\mathrm{CRH})$ : priming the placental clock," Peptides, vol. 27, no. 6, pp. 1457$1463,2006$.

[235] L. Duthie and R. M. Reynolds, "Changes in the maternal hypothalamic-pituitary-adrenal axis in pregnancy and postpartum: Influences on maternal and fetal outcomes," Neuroendocrinology, vol. 98, no. 2, pp. 106-115, 2013.

[236] A. M. Ronco, M. Urrutia, M. Montenegro, and M. N. Llanos, "Cadmium exposure during pregnancy reduces birth weight and increases maternal and foetal glucocorticoids," Toxicology Letters, vol. 188, no. 3, pp. 186-191, 2009.

[237] E. Kajantie, L. Dunkel, U. Turpeinen et al., "Placental 11 $\beta$ hydroxysteroid dehydrogenase-2 and fetal cortisol/cortisone shuttle in small preterm infants," Journal of Clinical Endocrinology and Metabolism, vol. 88, no. 1, pp. 493-500, 2003.

[238] M. Aufdenblatten, M. Baumann, L. Raio et al., "Prematurity is related to high placental cortisol in preeclampsia," Pediatric Research, vol. 65, no. 2, pp. 198-202, 2009.

[239] B. I. S. Federenko and P. D. Wadhwa, "Women's mental health during pregnancy influences fetal and infant," CNS Spectrums, vol. 9, pp. 198-206, 2004.

[240] S. L. Szanton, J. M. Gill, and J. K. Allen, "Allostatic load: a mechanism of socioeconomic health disparities?" Biological Research for Nursing, vol. 7, no. 1, pp. 7-15, 2005.

[241] J. Lesage, D. Hahn, M. Léonhardt, B. Blondeau, B. Bréant, and J. P. Dupouy, "Maternal undernutrition during late gestationinduced intrauterine growth restriction in the rat is associated 
with impaired placental GLUT3 expression, but does not correlate with endogenous corticosterone levels," Journal of Endocrinology, vol. 174, no. 1, pp. 37-43, 2002.

[242] C. D. Salpietro, S. Gangemi, P. L. Minciullo et al., "Cadmium concentration in maternal and cord blood and infant birth weight: a study on healthy non-smoking women," Journal of Perinatal Medicine, vol. 30, no. 5, pp. 395-399, 2002.

[243] M. N. Llanos and A. M. Ronco, "Fetal growth restriction is related to placental levels of cadmium, lead and arsenic but not with antioxidant activities," Reproductive Toxicology, vol. 27, no. 1, pp. 88-92, 2009.

[244] K. H. Al-Gubory, "Environmental pollutants and lifestyle factors induce oxidative stress and poor prenatal development," Reproductive BioMedicine Online, vol. 29, no. 1, pp. 17-31, 2014.

[245] E. V. Younglai, Y. J. Wu, and W. G. Foster, "Reproductive toxicology of environmental toxicants: emerging issues and concerns," Current Pharmaceutical Design, vol. 13, no. 29, pp. 3005-3019, 2007.

[246] A. V. Diez-Roux, "On genes, individuals, society, and epidemiology," American Journal of Epidemiology, vol. 148, no. 11, pp. 1027-1032, 1998.

[247] N. Auger, Z.-C. Luo, R. W. Platt, and M. Daniel, "Do mother's education and foreign born status interact to influence birth outcomes? Clarifying the epidemiological paradox and the healthy migrant effect," Journal of Epidemiology and Community Health, vol. 62, no. 5, pp. 402-409, 2008.

[248] A. Alberg, "The influence of cigarette smoking on circulating concentrations of antioxidant micronutrients," Toxicology, vol. 180, no. 2, pp. 121-137, 2002.

[249] K. Okumura and H. Tsukamoto, "Folate in smokers," Clinica Chimica Acta, vol. 412, no. 7-8, pp. 521-526, 2011.

[250] D. B. Kim, Y. S. Oh, K. D. Yoo et al., "Passive smoking in neversmokers is associated with increased: plasma homocysteine levels," International Heart Journal, vol. 51, no. 3, pp. 183-187, 2010.

[251] F. M. Haste, O. G. Brooke, H. R. Anderson et al., "Nutrient intakes during pregnancy: observations on the influence of smoking and social class," The American Journal of Clinical Nutrition, vol. 51, no. 1, pp. 29-36, 1990.

[252] S. B. Astley and D. G. Lindsay, "Conclusions," Molecular Aspects of Medicine, vol. 23, no. 1-3, pp. 287-291, 2002.

[253] M. C. Wang, S. Kim, A. A. Gonzalez, K. E. MacLeod, and M. A. Winkleby, "Socioeconomic and food-related physical characteristics of the neighbourhood environment are associated with body mass index," Journal of Epidemiology and Community Health, vol. 61, no. 6, pp. 491-498, 2007.

[254] H. K. Seligman, A. B. Bindman, E. Vittinghoff, A. M. Kanaya, and M. B. Kushel, "Food insecurity is associated with diabetes mellitus: results from the National Health Examination and Nutrition Examination Survey (NHANES) 1999-2002," Journal of General Internal Medicine, vol. 22, no. 7, pp. 1018-1023, 2007.

[255] E. J. Adams, L. Grummer-Strawn, and G. Chavez, "Food insecurity is associated with increased risk of obesity in California women," Journal of Nutrition, vol. 133, no. 4, pp. 1070-1074, 2003.

[256] J. Von Braun, H. Bouis, S. Kumar, and R. Pandya-Lorch, Improving Food Security of the Poor: Concept, Policy, and Programs, International Food Policy Research Institute, Washington, DC, USA, 1992.

[257] B. Laraia, E. Epel, and A. M. Siega-Riz, "Food insecurity with past experience of restrained eating is a recipe for increased gestational weight gain," Appetite, vol. 65, pp. 178-184, 2013.
[258] J. D. Parker, D. Q. Rich, S. V. Glinianaia et al., "The international collaboration on air pollution and pregnancy outcomes: initial results," Environmental Health Perspectives, vol. 119, no. 7, pp. 1023-1028, 2011.

[259] D. Rojas-Rueda, A. de Nazelle, O. Teixidó, and M. Nieuwenhuijsen, "Health impact assessment of increasing public transport and cycling use in Barcelona: a morbidity and burden of disease approach," Preventive Medicine, vol. 57, no. 5, pp. 573-579, 2013.

[260] P. Dadvand, A. de Nazelle, M. Triguero-Mas et al., "Surrounding greenness and exposure to air pollution during pregnancy: an analysis of personal monitoring data," Environmental Health Perspectives, vol. 120, no. 9, pp. 1286-1290, 2012.

[261] Z. Yao, Y. Zhang, X. Shen, X. Wang, Y. Wu, and K. He, "Impacts of temporary traffic control measures on vehicular emissions during the Asian Games in Guangzhou, China," Journal of the Air \& Waste Management Association, vol. 63, no. 1, pp. 11-19, 2013.

[262] H. Boogaard, N. A. H. Janssen, P. H. Fischer et al., "Impact of low emission zones and local traffic policies on ambient air pollution concentrations," Science of the Total Environment, vol. 435-436, pp. 132-140, 2012.

[263] L. E. Jackson, "The relationship of urban design to human health and condition," Landscape and Urban Planning, vol. 64, no. 4, pp. 191-200, 2003.

[264] C. A. Pope III, "Review: epidemiological basis for particulate air pollution health standards," Aerosol Science and Technology, vol. 32, no. 1, pp. 4-14, 2000.

[265] World Health Organization, Health Effects of Particulate Matter: Policy Implications for Countries in Eastern Europe, Caucasus and Central Asia, vol. 50, World Health Organization, Copenhagen, Denmark, 2013.

[266] O. Hänninen, A. B. Knol, M. Jantunen et al., "Environmental burden of disease in Europe: assessing nine risk factors in six countries," Environmental Health Perspectives, vol. 122, no. 5, pp. 439-446, 2014. 


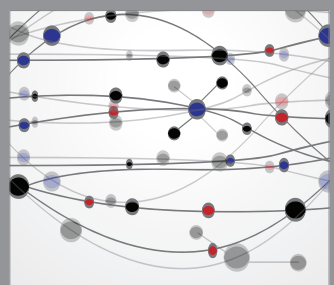

The Scientific World Journal
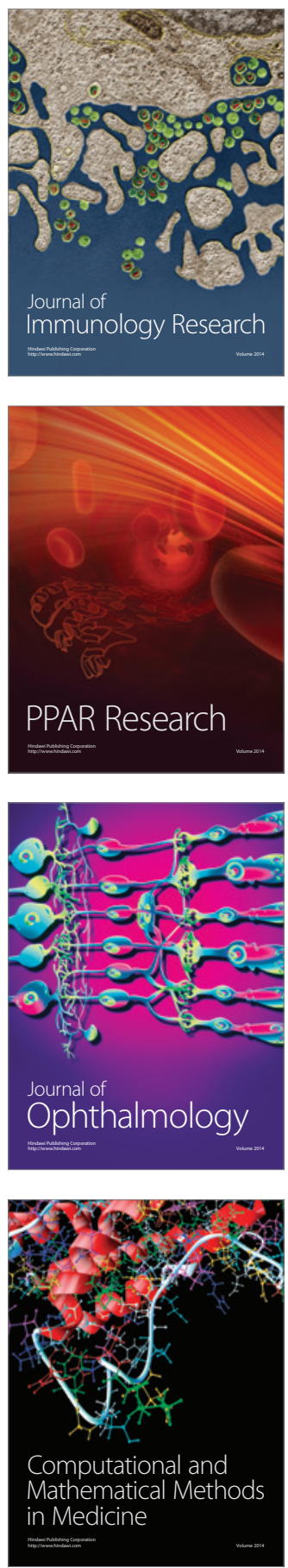

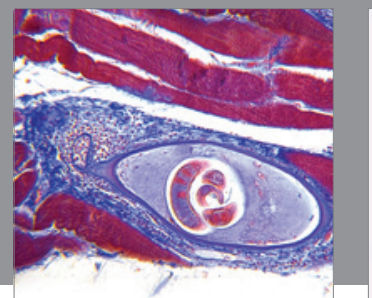

Gastroenterology

Research and Practice
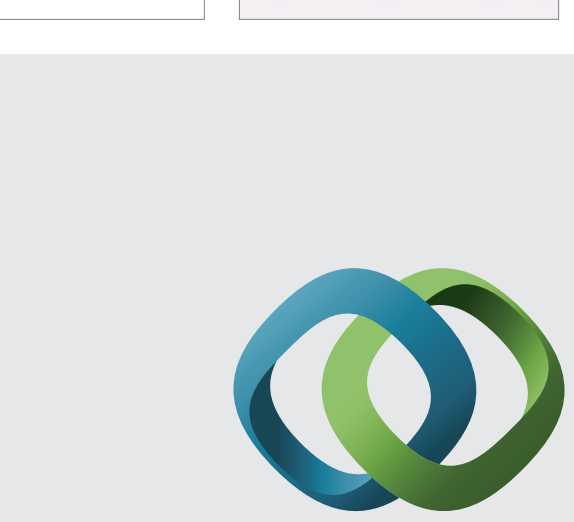

\section{Hindawi}

Submit your manuscripts at

http://www.hindawi.com
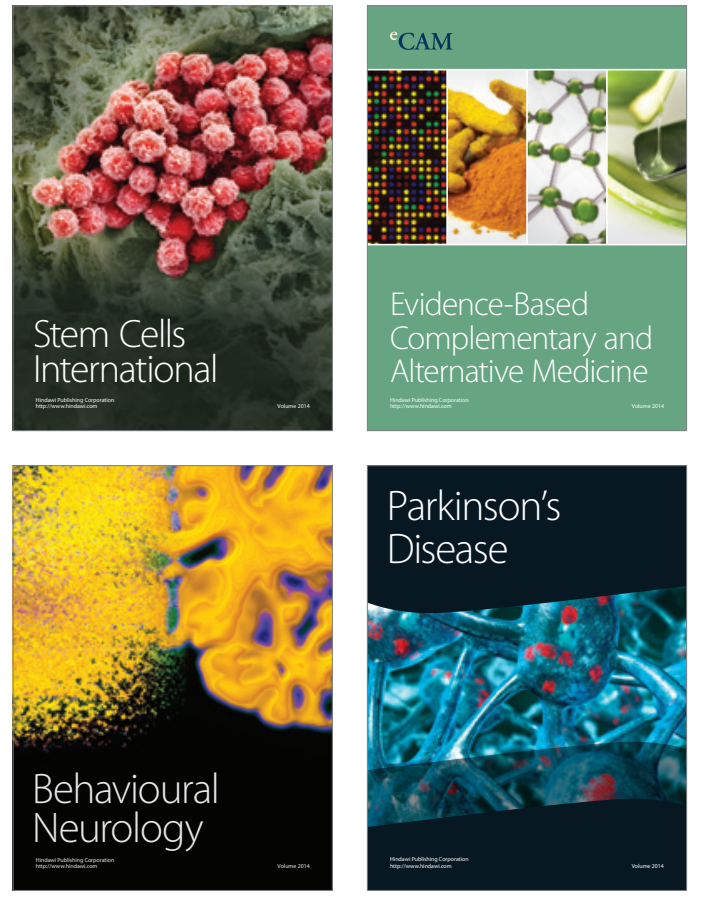
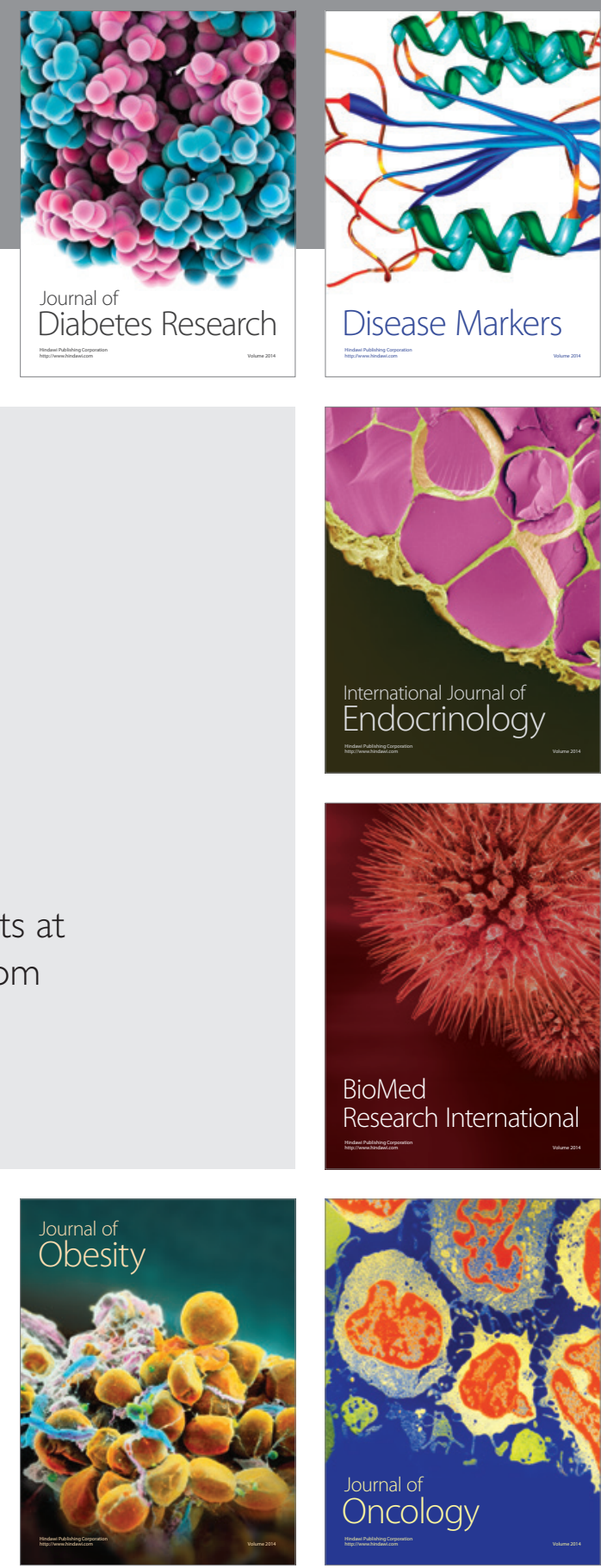

Disease Markers
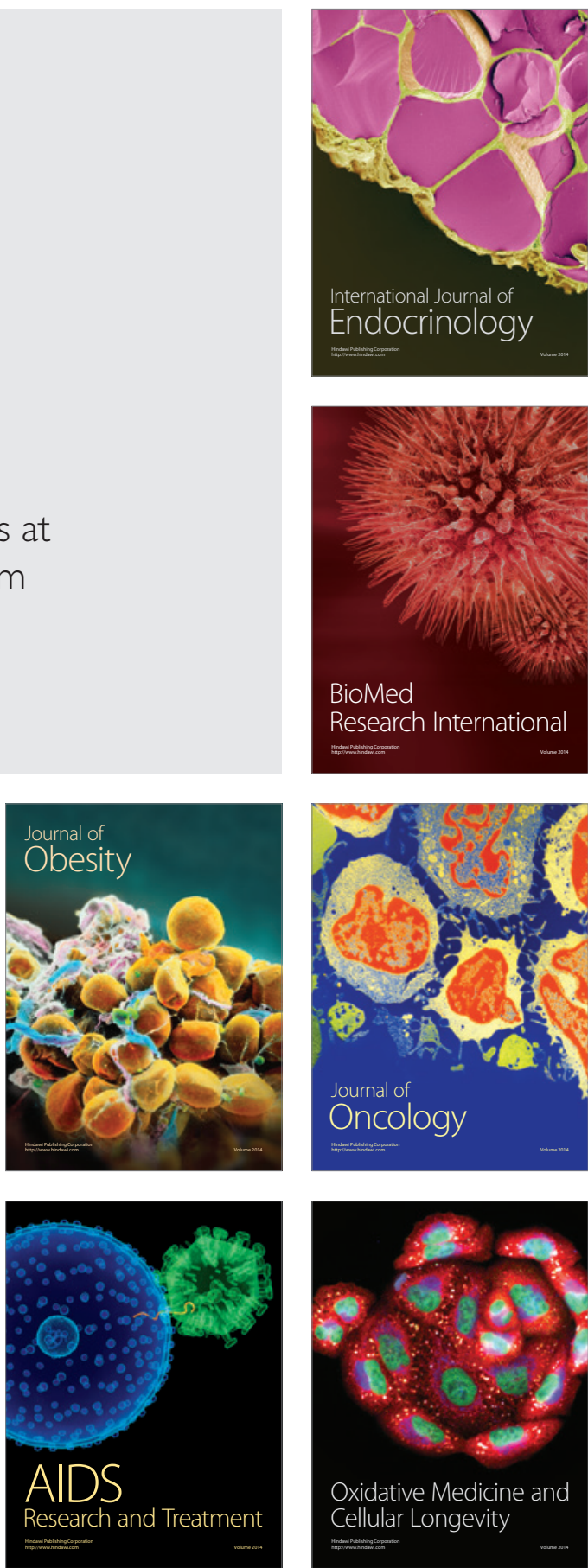